\title{
LA HOMOLOGACIÓN DE TÍTULOS UNIVERSITARIOS EXTRANJEROS EN ESPAÑA Y OTRAS FIGURAS AFINES ${ }^{1}$
}

\author{
José AlBerto ESPAÑA PÉREZ \\ Doctorando en Ciencias Jurídicas y Sociales \\ jose.alberto.espana@hotmail.com \\ Universidad de Málaga
}

\begin{abstract}
Resumen:
La adaptación de los estudios universitarios al denominado proceso de Bolonia dejaba sin resolver una importante cuestión: cómo homologar los títulos universitarios obtenidos en instituciones extranjeras o en centros españoles adscritos a un programa foráneo. El nuevo Real Decreto 967/2014, de 21 de noviembre, regula tal materia y establece los requisitos necesarios para que los estudios extranjeros puedan equipararse a los españoles; diferenciando entre tres figuras: homologación, declaración de equivalencia y convalidación. Con respecto a la primera ésta se considerará cuando se quiera homologar un título extranjero a una titulación universitaria española que dé acceso a una profesión regulada; si el título no habilita para el ejercicio profesional se optará por la declaración de equivalencia a un nivel académico y a la titulación correspondiente y, para el resto de supuestos, habrá que acudir a la convalidación.

Lejos de lo que pueda parecer, el reconocimiento de titulaciones y estudios extranjeros es un instrumento fundamental para lograr la movilidad de estudiantes y la atracción de talento a España. Por ello, el presente artículo aborda la nueva regulación en materia de validez de titulaciones superiores extranjeras en España a raíz de la entrada en vigor del Real Decreto 967/2014, haciendo especial hincapié entre las distintas figuras que diferencia el texto normativo y reparando en la evolución que ha sufrido los sistemas para dar efectividad a los títulos extranjeros en nuestro país.
\end{abstract}

Palabras claves: Homologación, equivalencia, convalidación, reconocimiento, títulos universitarios extranjeros.

\begin{abstract}
:
The adaptation of the university studies to the Bologna process did not solve an important question: how post-secondary degrees obtained in foreign institutions or Spanish centers were written through a program for sports. The new Royal Decree 967/2014, November 21, regulates the matter and establishes the necessary requirements so that foreign studies can be compared to Spaniards; differentiating between three figures: homologation, declaration of equivalence and validation. With regard to the first, this will be considered when you have a foreign degree to a Spanish university degree that gives access to a regulated profession; if the title does not qualify for professional practice, the declaration of equivalence is chosen at an academic level and the corresponding degree and, for the rest of the cases, validation.
\end{abstract}

\footnotetext{
${ }^{1}$ Este estudio se realiza en el marco Grupo de Investigación de la Junta de Andalucía SEJ-410: "Estudios jurídicos interdisciplinares avanzados: servicios colectivos".

REJIE Nueva época: Revista Jurídica de Investigación e Innovación Educativa Núm.18, Junio 2018, pp. 81-118

[En línea] http://www.revistas.uma.es/index.php/rejie
} 
Far from what may seem, the recognition of foreign degrees and studies is a fundamental instrument for the mobility of students and the attraction of talent in Spain. Therefore, this article will address the new regulation on the validity of higher degrees in Spain following the entry into force of Royal Decree 967/2014, with special emphasis on the different figures that differentiate the normative text and repairing the evolution that has undergone systems to give effectiveness to foreign titles in our country.

Keywords: Homologation, equivalence, validation, recognition, foreign university degrees.

Sumario: 1. Introducción. 2. Aproximaciones conceptuales. 3. Títulos académicos y efectos oficiales. 3.1. Marco normativo y características de los títulos universitarios españoles. 3.2. Efectos oficiales en España de los títulos universitarios extranjeros. 4. El régimen de homologación de títulos universitarios extranjeros en España y figuras afines. 4.1. Homologación de títulos extranjeros y las libertades comunitarias. 4.2. Homologación a un título o a un grado académico. 4.3. El actual marco jurídico de la homologación: distinción de figuras afines. 4.3.1. La homologación, declaración de equivalencia y convalidación. 4.3.2. Procedimiento de correspondencia a nivel MECES para favorecer la movilidad en el extranjero. 4.3.3. Características formativas y causas de exclusión para la homologación de títulos extranjeros y figuras afines. 5. Procedimiento de homologación, declaración de equivalencia, convalidación de títulos extranjeros en España y correspondencia a nivel MECES. 6. Conclusiones. Bibliografía

\section{Introducción.}

La homologación de títulos universitarios extranjeros es un complejo procedimiento administrativo cuya principal dificultad radica en la implicación de dos sistemas educativos, el del país de origen y aquel en el que se pretende efectuar la homologación. El hecho de que se vean involucrados dos Estados con soberanía propia en la planificación educativa interna aumenta la complejidad de equiparar los estudios realizados, incluso en el ámbito europeo donde, pese a los intentos, no se ha logrado alcanzar una uniformidad plena entre los distintos programas educativos de cada Estado miembro ${ }^{2}$.

Hace ya diecinueve años diversos Estados europeos ratificaron la denominada Declaración de Bolonia ${ }^{3}$, sentando las bases para la construcción de un Espacio Europeo de Educación Superior (EEES), el cual, propugnaba la calidad, la movilidad, la diversidad y la competitividad como ejes centrales de su estructura ${ }^{4}$. El llamado proceso de Bolonia se orienta, según se plasmó en su declaración original, a la conversión del sistema Europeo de Formación Superior en un polo de atracción para estudiantes y

\footnotetext{
${ }^{2}$ Algunos autores se muestran escépticos frente a la pretendida convergencia educativa de Europa. Vid, FERNANDEZ LIRIA C. y SERRANO GARCÍA C. (2009), El Plan Bolonia. Madrid: Catarata. p.19.

${ }^{3}$ Vid, Declaración conjunta de los ministros europeos de enseñanza de 19 de junio de 1999. [En línea] http://eees.umh.es/contenidos/Documentos/DeclaracionBolonia.pdf.

${ }^{4}$ SALABURU, P. (2007), La Universidad en la encrucijada. Madrid: Academia Europea de Ciencias y Artes, pp.100-108.
} 
docentes de otros países ${ }^{5}$. Para LOPERENA ROTA el proyecto giraba en torno a dos ideas principales: la globalización y la construcción europea ${ }^{6}$. Con respecto a la primera, la movilidad estudiantil es un fenómeno que se ha incrementado en los últimos años, sobre todo, de jóvenes universitarios. Un hecho que aumenta el interés en una adecuada regulación de homologación de títulos educativos superiores que agilicen el proceso y posibiliten un sistema relativamente simple. Por otro lado, la falta de cohesión europea dificulta la solidez de una verdadera convergencia entre los distintos Estados miembros. La carencia de un sentimiento ciudadano de pertenencia a una comunidad europea, unida a la propia visión cortoplacista y nacionalista de los gobernantes de cada Estado contribuye desfavorablemente a la construcción de una verdadera unión en Europa ${ }^{7}$.

Entre otros, el proceso de Bolonia defiende la adopción de un sistema fácilmente comparable de titulaciones que permita la movilidad de estudiantes, docentes e investigadores; eliminando los obstáculos existentes dentro del espacio europeo ${ }^{8}$. Y es en este sentido, donde la homologación de títulos extranjeros puede convertirse en un instrumento esencial para reforzar el papel institucional de la Unión Europea y propiciar la aplicabilidad práctica del proyecto europeo ${ }^{9}$. Si bien es cierto que con la llegada de este proceso se impuso la idea de que los títulos obtenidos en los diferentes Estados miembros iban a tener efectos sin ningún tipo de procedimiento administrativo en España, finalmente, la realidad ha sido bien distinta ${ }^{10}$. Lo cierto es que el reconocimiento de titulaciones extranjeras de educación superior precisa de un acto expreso por la autoridad competente. Así pues, a día de hoy, pese a la convergencia europea, los títulos extranjeros, carecen de efectos oficiales en España sin el previo proceso de homologación, equivalencia o convalidación.

\footnotetext{
${ }^{5}$ Aunque algunos autores sostienen otra idea, como la apuesta por un modelo universitario de "educación para la renta”. Vid, BOK, D. (2010), Universidades a la venta: la comercialización de la educación superior. Valencia: Publicacions de la Universitat de València.

${ }^{6}$ LOPERENA ROTA, D. (2010), "Los retos de Bolonia", Revista Vasca de Administración Pública, $\mathrm{n}^{\circ}$ 86, p. 121.

${ }^{7}$ No obstante es preciso señalar que el proceso de Bolonia se concibe como uno de los retos más ambiciosos a los que se ha enfrentado la educación superior en Europa. De la envergadura del proceso y sus desafíos reflexiona FERNANDEZ-LLEBREZ, F. (2010), "El Plan Bolonia y la reforma de la Universidad"; Pagina Abierta, no 207. [En línea] http://www.pensamientocritico.org/ferfer0410.html.

${ }^{8}$ Pese a todo, en España algo más de 5 por ciento de los estudiantes universitarios han sido extranjeros en el curso 2014-2015, según los últimos datos difundidos por el Ministerio de Educación. Vid, "Datos básicos del sistema universitario español. Curso 2015-2016”, p. 101. [En línea] https://www.mecd.gob.es/dms/mecd/servicios-alciudadanomecd/estadisticas/educacion/universitaria/datos-cifras/datos-y-cifras-SUE-2015-16-web-.pdf. 9 Algunos autores señalan, además, los problemas económicos y los diferentes criterios de exigencia europeos en el ámbito de la movilidad universitaria. Vid, SALAS VELASCO, M. (2010), "Financiación y crítica de la Universidad española actual", Crítica, año 60, nº.969, pp. 22-27. [En línea] http://www.revista-

critica.com/administrator/components/com_avzrevistas/pdfs/03bf4d8eabadb888af703827454d0b86-969-

La-Universidad-y-sus-contradicciones---Despu--s-de-Bolonia--qu-----sept.oct\%202010.pdf.

${ }^{10}$ FERNANDEZ LIRIA C. y SERRANO GARCÍA C., Op. cit., p.18. "La creación de un Espacio Europeo de Educación Superior (EEES) [...] se empezó a vender como un auténtico paraíso en el que los alumnos viajarían por toda Europa, cursando asignaturas en diversos centros que serían inmediatamente homologables porque se expresarían en una nueva unidad de medida, algo así como el 'euro' del mundo académico: los créditos ECTS. [...] Pretenden medir lo que es imposible de medir: cuánto tiempo cuesta aprender algo bien."
} 
En nuestro país se han promulgado hasta tres reales decretos para desarrollar la efectividad de los títulos de educación superior extranjeros en España en los últimos treinta años, en aras, a lograr la adaptación a los diferentes cambios educativos que se han ido sucediendo ${ }^{11}$. La última reforma relativa a tal materia ha tenido ocasión con la adaptación del sistema de educación español al proceso de Bolonia ${ }^{12}$. La Ley Orgánica de Universidades (LOU) ${ }^{13}$ se refiere al EEES (arts. 87 y ss.) pero dejaba sin resolver el procedimiento para validar los títulos superiores extranjeros en nuestro país. En este contexto se promulgó el Real Decreto $967 / 2014^{14}$, que regula el sistema de homologación, equivalencia y convalidación de títulos extranjeros, y el cual, despertó curiosidad y también numerosas críticas por parte de determinados colegios profesionales $^{15}$.

Desde la entrada en vigor de este Real Decreto, a finales de 2014, se llenó la laguna existente en materia de reconocimiento de titulaciones extranjeras en España a raíz de la desaparición del catálogo oficial de títulos universitarios ${ }^{16}$ que impuso el proceso de Bolonia. Así, este nuevo Real Decreto regula dos procedimientos bien diferenciados que se articulan en los Capítulos II y III del texto. El primero de ellos se refiere al procedimiento para la homologación, declaración de equivalencia a titulación y a nivel académico universitario oficial y para la convalidación de estudios extranjeros de educación superior. El segundo se centra en el procedimiento para determinar la correspondencia a los niveles del marco español de cualificaciones para la educación

\footnotetext{
${ }^{11}$ Para una visión crítica con las continuas reformas legislativas en materia educativa vid, CATALÁ RUBIO, S. (2015), “Algunos elementos de reflexión sobre la Universidad española”, Encuentros multidisciplinares, $\quad \mathrm{n}^{\circ} \quad 49, \quad$ pp. $41-6 . \quad$ [En $\quad$ línea] https://repositorio.uam.es/bitstream/handle/10486/678636/EM_49_5.pdf?sequence=1\&isAllowed=y.

12 Sobre la situación actual de la Universidad española desde un recorrido histórico vid, HERNÁNDEZ DÍAZ, J.M. (2014), "Los espacios de la universidad española", Cuadernos del Instituto Antonio de Nebrija de Estudios sobre la Universidad. CIAN, vol. 17, no. 1, pp. 81-100. [En línea] https://erevistas.uc3m.es/index.php/CIAN/article/view/1971/940.

${ }^{13}$ Ley Orgánica 6/2001, de 21 de diciembre, de Universidades, modificada por la Ley Orgánica 4/2007, de 12 de abril. [BOE núm.89, de 13 de abril de 2007].

${ }^{14}$ Real Decreto 967/2014, de 21 de noviembre, por el que se establecen los requisitos y el procedimiento para la homologación y declaración de equivalencia a titulación y a nivel académico universitario oficial y para la convalidación de estudios extranjeros de educación superior, y el procedimiento para determinar la correspondencia a los niveles del marco español de cualificaciones para la educación superior de los títulos oficiales de Arquitecto, Ingeniero, Licenciado, Arquitecto Técnico, Ingeniero Técnico y Diplomado. [BOE núm. 283, de 22 de noviembre de 2014].

${ }^{15}$ FERLUGA, G. "Avalancha de recursos contra la homologación de títulos extranjeros". Cinco Días. 2 de marzo de 2015 [En 2 línea] https://cincodias.elpais.com/cincodias/2015/02/27/economia/1425049969_540904.html. Vid, recursos contra el Real Decreto 967/2014: recurso contencioso-administrativo ante el Tribunal Supremo (Sala de lo Contencioso-Administrativo, Sección 4a) núm. 964/2014, 9/2015, 14/2015, 15/2015, 17/2015, 19/2015, 20/2015, 22/2015, 24/2015, 26/2015 y 29/2015.

${ }^{16}$ Un sistema que establecía una lista cerrada con los títulos superiores que las Universidades podían expedir. Fuera del mismo, no era posible la homologación de estudios universitarios que hubieran sido cursados en el extranjero. Sobre las consecuencias de la desaparición del catálogo de títulos oficiales y el actual sistema vid, VAN GRIEKEN SALVADOR, R. (2014), "El Espacio Europeo de Educación Superior, la gestión de la calidad y su impacto en la oferta de títulos universitarios", Nueva revista de política, cultura y arte, $\mathrm{n}^{\mathrm{o}}$ 151, 2014, pp. 277-288. [En línea] https://reunir.unir.net/bitstream/handle/123456789/4444/E1\%20espacio\%20europeo.pdf?sequence=1\&isA llowed $=\mathrm{y}$.
} 
superior de los títulos oficiales de Arquitecto, Ingeniero, Licenciado, Arquitecto Técnico, Ingeniero Técnico y Diplomado.

La consolidación del proceso de Bolonia y el retorno del fenómeno de la inmigración a nuestro país tras sortearse los escollos de la crisis económica han propiciado un nuevo aumento en el interés en la homologación, y figuras afines, de títulos universitarios extranjeros en España ${ }^{17}$. Por ello, el presente artículo analiza el régimen jurídico actual de los sistemas para dar validez a los títulos extranjeros en España, junto con sus implicaciones y efectos, prestando especial atención a su evolución normativa y a los conceptos jurídicos que definen tal procedimiento administrativo.

\section{Aproximaciones conceptuales.}

Antes de analizar el vigente texto normativo que ordena los diferentes sistemas para dar validez a los títulos extranjeros en España y sus normas predecesoras, es preciso dedicar un epígrafe a definir aquellos conceptos jurídicos relacionados con el reconocimiento de titulaciones foráneas en nuestro país y que aparecen con gran asiduidad a lo largo de este artículo.

En primer lugar, es pertinente concretar qué se entiende por título de educación superior. Así pues, un título académico es un documento de carácter oficial que certifica la superación de unos estudios oficiales y es expedido por la autoridad competente ${ }^{18}$. El derogado Real Decreto 1665/1991 ${ }^{19}$ que regulaba el reconocimiento de los títulos universitarios entre Estados miembros de la Unión Europea ofrecía una definición completa e inequívoca de lo que entendía por título ${ }^{20}$. No obstante, nuestro ordenamiento jurídico actual no define de forma explícita qué debe entenderse por título universitario, sin embargo, tal concepto se puede deducir de la lectura de distintas disposiciones localizadas en la vigente Ley Orgánica de Universidades y el Real

\footnotetext{
${ }^{17}$ Además algunos autores señalan otros retos a los que tiene que hacer frente la Universidad española a raíz de la implantación del EEES vid, LASPALAS, J. (2002), "La eterna 'crisis' universitaria: a propósito de dos libros recientes”, ESE. Estudios sobre educación, $\mathrm{n}^{\circ}$ 2, p.207-2I5. [En línea] http://dadun.unav .edu/bitstream/10171/8106/1/Notas\%205.pdf.

${ }^{18}$ La Sentencia del Tribunal Supremo de 3 junio 2002 (Sala de lo Contencioso-Administrativo, Sección $7^{a}$ ), recurso de casación núm. 3486/1997, ponente: Sr. Manuel Goded Miranda; considera que los títulos de carácter académico tienen que haber sido expedidos por Universidades "que es como hay que entender el concepto de título académico".

${ }^{19}$ Real Decreto 1665/1991, de 25 de octubre, por el que se regula el sistema general de reconocimiento de los títulos de Enseñanza Superior de los Estados miembros de la Comunidad Económica Europea que exigen una formación mínima de tres años de duración. [BOE núm. 280, de 22 de noviembre de 1991].

${ }^{20}$ Artículo 1. a) del Real Decreto 1665/1991, de 25 de octubre, por el que se regula el sistema general de reconocimiento de los títulos de Enseñanza Superior de los Estados miembros de la Comunidad Económica Europea que exigen una formación mínima de tres años de duración: "cualquier título, certificado u otro diploma o conjunto de los mismos, expedido por una Autoridad competente en un Estado miembro, que acredite que el titular ha superado un ciclo de estudios postsecundarios de una duración mínima de tres años en una Universidad, en un Centro de Enseñanza Superior o en otro Centro del mismo nivel de formación y que posee las cualificaciones profesionales requeridas para acceder a una profesión regulada en dicho Estado miembro, siempre que la formación haya sido adquirida principalmente en la Comunidad o el titular tenga una experiencia profesional de tres años acreditada por el Estado miembro que haya reconocido el título".
} 
Decreto 1393/2007 que regula la enseñanza universitaria ${ }^{21}$. Así, son títulos universitarios de carácter oficial y validez en todo el territorio nacional aquellos cuyas directrices y condiciones hayan sido establecidas por el Gobierno, según se desprende del artículo 35.1 de la LOU. Los títulos universitarios oficiales tienen plenos efectos académicos y profesionales. Según lo dispuesto en el Real Decreto 1393/2007 los títulos universitarios "surtirán efectos académicos plenos y habilitarán, en su caso, para la realización de actividades de carácter profesional reguladas, de acuerdo con la normativa que en cada caso resulte de aplicación" (artículo 4 del Real Decreto 1393/2007). Asimismo, el artículo 3.2 del Real Decreto 1393/2007 prevé que estos títulos oficiales sean expedidos, en nombre del Rey, por el Rector/a de la Universidad en que se hubiesen concluido las enseñanzas que den derecho a su obtención, de acuerdo con los requisitos básicos que, respecto a su formato, texto y procedimiento de expedición, se establezcan por el Gobierno. Será, pues el Ejecutivo quien regule las condiciones de cada uno de los títulos oficiales partiendo de la estructura de las enseñanzas universitarias previstas en el artículo 37 de la LOU (Grado, Máster y Doctorado). De esta forma, los títulos universitarios se caracterizan por tener carácter oficial y validez en todo el territorio nacional; seguir las directrices y condiciones que fije el Gobierno y ser expedidos por el correspondiente Rector/a de la Universidad.

La obtención de estos títulos oficiales exigirá la superación de los correspondientes estudios (artículo 37 de la LOU) conforme a los planes ajustados a las criterios establecidos por el Gobierno (con especial atención a los protocolos de la Agencia Nacional de Evaluación de la Calidad y Acreditación) junto a la correspondiente autorización de la Comunidad Autónoma y la a verificación del Consejo de Universidades de que los estudios siguen las condiciones del Ejecutivo (artículo 35.2 de la LOU). Una vez determinados, se establecerá el carácter oficial del título y se incorporará al Registro de Universidades, Centros y Títulos ${ }^{22}$ por orden del Gobierno (artículo 35.3 de la LOU). Finalmente, el plan de estudios se publicará en el Boletín Oficial del Estado y en el diario oficial de la Comunidad Autónoma por orden del Rector de la Universidad (artículo 35.4 de la LOU). Además, según se establece en Real Decreto 1393/2007 los títulos universitarios oficiales deberán someterse a un procedimiento de evaluación cada cierto tiempo con el fin de mantener su acreditación (artículo 24 del Real Decreto 1393/2007) ${ }^{23}$.

Junto a los títulos universitarios de carácter oficial y válidos en todo el territorio nacional, existen una serie de enseñanzas de educación superior cuya superación no equivale a títulos de dicho carácter sino a otras denominaciones. Son los designados como títulos y diplomas propios de las Universidades. La vigente LOU reconoce la

\footnotetext{
${ }^{21}$ Real Decreto 1393/2007, de 29 de octubre, por el que se establece la ordenación de las enseñanzas universitarias oficiales. [BOE núm. 260, de 30 de octubre de 2007].

${ }^{22}$ Se refiere al Registro de Universidades, Centros y Títulos (RUCT) de carácter público y creado por el Real Decreto 1509/2008, de 12 de septiembre, por el que se regula el Registro de Universidades, Centros y Títulos. [BOE núm. 232, de 25 de septiembre de 2008]. En él constan inscritos los títulos de Grado, Máster y Doctorado oficiales.

${ }^{23}$ Sobre el procedimiento de seguimiento y la renovación de la acreditación de los títulos oficiales vid, MUÑOZ-CANTERO, J.M. y POZO, C. (2014), "El escenario de la calidad en la Universidad española: de dónde venimos y hacia dónde vamos", Revista Electrónica

Interuniversitaria de Formación del Profesorado, $\mathrm{n}^{\mathrm{o}} 17$ (3), pp.1-16. [En línea] http://revistas.um.es/reifop/article/view/204011/165141.
} 
autonomía universitaria para la expedición de sus diplomas y títulos propios (artículo 2.2.g) de la LOU), de manera que las entidades universitarias podrán establecer enseñanzas conducentes a la obtención de cualquier otro título, diferente de los oficiales (artículo 34.1 de la LOU). Al amparo de estas disposiciones se permite la creación de diplomas y títulos por cada Universidad ${ }^{24}$.

Al efecto, los títulos propios son enseñanzas que ofrecen las Universidades con el objeto de impartir actividad formativa que no se contempla en las diferentes titulaciones universitarias, pero que no poseen los efectos que la ley establece para las titulaciones oficiales, es decir, las establecidas por el Gobierno. Aunque el Real Decreto 1509/2008 por el que se regula el Registro de Universidades, Centros y Títulos (RUCT) contempla la posibilidad de registrar los títulos propios (artículo 17 del Real Decreto 1509/2008). En este sentido, el Pleno del Consejo de Universidades ${ }^{25}$, en julio de 2010, acordó los tipos y las condiciones comunes que debían poseer los títulos propios, con los objetivos de unificar los criterios y características de los diferentes cursos ofrecidos para facilitar su reconocimiento entre Universidades y establecer unas condiciones y directrices mínimas para poder optar al registro de estos títulos en el RUCT. Dicho acuerdo fue refrendado posteriormente por la Conferencia General de Política Universitaria, y adoptado por la mayor parte de las Universidades que ofrecen cursos de formación permanente.

Una vez clarificado el concepto de título oficial y su distinción respecto a los títulos propios, procede que nos detengamos en los conceptos de homologación, equivalencia y convalidación, que, a veces, de forma incorrecta se utilizan indistintamente. Así, el nuevo Real Decreto 967/2014 que ordena los sistemas para dar efectividad a los títulos superiores extranjeros en España diferencia estas tres figuras y señala un procedimiento específico para cada una de ellas.

En primer lugar, por homologación se entiende todo procedimiento para identificar un título extranjero de educación superior a los correspondientes títulos oficiales universitarios españoles de Grado y Máster que den acceso a una profesión regulada y cuya posesión sea necesaria para el acceso a la misma (art. 1.a).1. ${ }^{\circ}$ del Real Decreto 967/2014). De manera que el concepto de homologación sólo se reputa de aquellas titulaciones que en España habiliten para el ejercicio profesional. Así, la homologación es el reconocimiento oficial de la formación superada para la obtención de un título extranjero, equiparable a la exigida para la obtención de un título español que habilite para el ejercicio de una profesión regulada (art. 4.a) del Real Decreto 967/2014).

Por equivalencia se entiende aquel procedimiento para equiparar títulos extranjeros de educación superior a las titulaciones universitarias oficiales, que no den acceso a

\footnotetext{
${ }^{24}$ Sobre la autonomía universitaria y la elaboración de los planes de estudios vid, AGUDO ZAMORA, M.J. (2015), "La estructura $3+2$ en los títulos universitarios como amenaza y oportunidad de desarrollo del derecho a la autonomía académica de las Universidades", Revista General de Derecho Constitucional, $\mathrm{n}^{\mathrm{o}}$. 21. [En línea] http://www.iustel.com/v2/revistas/detalle_revista.asp?id_noticia=416713.

${ }^{25}$ Vid, Acuerdo del Pleno del Consejo de Universidades del día 6 de julio de 2010, refrendado por la Conferencia General de Política Universitaria en su sesión del día 7 de julio de 2010. "Las Universidades y la Formación Permanente en España". [En línea] http://ruepep.org/wp-content/uploads/2012/05/2010formacion-permanente-acuerdo-cu-cgpu1.pdf.
} 
profesión regulada, a un nivel académico universitario (Grado o Máster) y a las ramas de conocimiento y campos específicos recogidos en el Anexo II Real Decreto 967/2014 (Artes y humanidades, Ciencias Sociales y Jurídicas, Ciencias, Ingeniería y Arquitectura y Ciencias de la Salud), según se establece en el artículo 1.a) 2. ${ }^{\circ}$ de la mencionada norma. Es decir, la equivalencia supone el reconocimiento oficial de la formación superada para la obtención de un título extranjero, como equivalente a la exigida para la obtención de un nivel académico (en función de los niveles en que se estructuran los estudios universitarios españoles), así como, a las titulaciones correspondientes a un área y campo incluido en el Real Decreto en los que pueden agruparse las diferentes titulaciones oficiales universitarias españolas, con exclusión de los efectos profesionales respecto de aquellos títulos susceptibles de obtenerse por homologación (art.4.b) del Real Decreto 967/2014).

Por último, la convalidación alude al procedimiento para convalidar estudios extranjeros (hayan terminado o no con la obtención de un título) por estudios universitarios parciales (artículo 17 y 18.1. del Real Decreto 967/2014). Es decir es el reconocimiento oficial de la validez de estudios superiores realizados en el extranjero, hayan finalizado o no con un título, respecto de estudios universitarios españoles que permitan proseguir dichos estudios en una Universidad española (art. 4.g) del Real Decreto 967/2014).

\section{Títulos académicos y sus efectos oficiales}

\subsection{Marco normativo y características de los títulos universitarios españoles}

El sistema por el cual un título académico extranjero puede equiparse a uno español es un complejo procedimiento que implica a dos sistemas educativos, es decir, a dos Estados con soberanía propia sobre su planificación educativa interna. Incluso en el ámbito europeo donde se ha intentado forzar una cooperación e integración entre los diferentes Estados miembros no existe un sistema educativo único como sí ocurre en el ámbito monetario. Así pues, las diferencias existentes entre los distintos modelos de educación provocan una gran dificultad a la hora de dar efectividad a las titulaciones académicas procedentes de otros países. Es más “el propio concepto de 'título', entendido como el conjunto de derechos académicos y profesionales que se vinculan al mismo, varía enormemente de unos sistemas educativos a otros" ${ }^{\text {"26. }}$.

El artículo 149.1.30. ${ }^{\text {a }}$ de la Constitución atribuye la regulación de las condiciones de obtención, expedición y homologación de títulos académicos y profesionales a la competencia exclusiva del Estado. Esa disposición, junto a lo dispuesto en el artículo 148 de la Constitución y en los Estatutos de Autonomía, delimita la distribución de competencias en esta materia ${ }^{27}$.

\footnotetext{
${ }^{26}$ GONZÁLEZ MIGUEL, R. (2007), "Homologación, convalidación y reconocimiento de títulos y estudios Extranjeros en España". Revista de Derecho de la Unión Europea, nº 12, p. 88.

${ }^{27}$ La Carta Magna española establece las atribuciones que corresponden en exclusiva al Estado y aquellas que podrán atribuirse a los entes descentralizados. Atendiendo al sistema competencial español podemos encontrar: competencias exclusivas del Estado, en virtud del artículo 149 de la Constitución; competencias que pueden ser asumidas por las Comunidades Autónomas, en virtud de la delimitación competencial que establece el artículo 148 y 149 de la Constitución; y por último, las restantes competencias, que no están reservadas en exclusiva al Estado y podrán ser asumidas por las Comunidades
} 
En relación al marco normativo que regula los títulos universitarios españoles hay que hacer referencia, en primer lugar, a la vigente LOU, la cual, reconoce la autonomía universitaria para la expedición de los títulos de carácter oficial y validez en todo el territorio nacional y de sus diplomas y títulos propios (art. 2.2.g) de la LOU). Además, en el Título VI la Ley establece una nueva estructuración de las enseñanzas y títulos universitarios oficiales que permite adaptar el sistema universitario al proceso de convergencia europeo, conteniendo la actual regulación de los títulos expedidos por las Universidades, diferenciando entre oficiales y propios. Siguiendo los principios sentados por la citada Ley se promulgó el Real Decreto 1393/2007 que ordena las enseñanzas universitarias. Esta norma desarrolla la estructura de los estudios superiores y la verificación y acreditación de los títulos universitarios españoles.

La normativa referente a la expedición de los títulos universitarios se localiza en el Real Decreto $1002 / 2010^{28}$. Tal texto contempla el procedimiento de expedición, así como las características que deben poseer los títulos en función de los diferentes niveles universitarios oficiales. Además crea también el Registro Nacional de Titulados Universitarios Oficiales que integra los datos concernientes de los futuros egresados de las Universidades españolas que concluyan sus estudios de Grado, Máster o Doctorado y determina los contenidos del Suplemento Europeo inherentes a los títulos académicos oficiales de conformidad al Real Decreto $1044 / 2003^{29}$ que regula el procedimiento para la expedición por las Universidades del Suplemento Europeo al Título ${ }^{30}$. Por último, el Real Decreto 1509/2008 regula el Registro de Universidades, Centros y Títulos, de carácter público, donde se inscriben los títulos oficiales con validez en todo el territorio nacional, aunque también se pueden inscribir, sólo a efectos informativos, otros títulos que cursen las Universidades.

Los títulos oficiales, expedidos por el Rector/a de la Universidad en nombre del Rey, corresponden a las enseñanzas universitarias oficiales de Grado, Máster y Doctorado. El soporte en que se imprimen, su formato, su texto ${ }^{31}$ y todo lo relativo al procedimiento de expedición se encuentra regulado en el Real Decreto 1002/2010 32 .

Autónomas si así lo establecen en sus propios Estatutos, en virtud de la cláusula residual del artículo 149.3 de la Constitución.

${ }^{28}$ Real Decreto 1002/2010, de 5 de agosto, sobre expedición de títulos universitarios oficiales. [BOE núm. 190, de 6 de agosto de 2010].

${ }^{29}$ Real Decreto 1044/2003, de 1 de agosto, por el que se establece el procedimiento para la expedición por las Universidades del Suplemento Europeo al Título. [BOE núm. 218, de 11 de septiembre de 2003].

${ }^{30}$ El Suplemento Europeo al Título es el documento que acompaña a cada uno de los títulos universitarios de carácter oficial, con la información unificada, personalizada para cada titulado universitario, sobre los estudios cursados, los resultados obtenidos, las capacidades profesionales adquiridas y el nivel de su titulación en el sistema nacional de educación superior (artículo 3 del Real Decreto 1044/2003).

${ }^{31}$ Según el artículo 16 del Real Decreto 1002/2010 los títulos se imprimirán en papel cartulina de material especial, con determinadas claves de autenticidad y de idéntico tamaño para todos ellos. Además llevarán el Escudo Nacional en el ángulo superior izquierdo. No obstante, las Universidades podrán adoptar, para los títulos que expidan, los atributos, colores, orlas y demás grafismos que estimen convenientes, así como incorporar a los mismos su propio escudo u otros, aunque en un tamaño inferior al del Escudo Nacional. Los títulos deben llevar impreso todo su texto, así como la firma del Rector/a de la Universidad correspondiente. Junto con ello, en el anverso del título deberán de figurar una serie de datos que se clarifican en el artículo 17 de la mencionada norma, tales como la referencia expresa a que el título se expide en nombre del Rey; nombre y apellidos de la persona interesada; lugar y fecha de nacimiento, así 
No obstante, la estructuración de la enseñanza universitaria se implantó, principalmente, con la Ley de Reforma Universitaria de $1983^{33}$, la cual, instauró en España una Universidad más diversificada y descentralizada de la que hasta entonces existía. Con ella, "los objetivos de la Universidad española se podían resumir en tres grandes ejes: la organización democrática de la Universidad, su inserción en el entorno social y su modernización científica y docente" ${ }^{34}$. Consecutivamente se iniciaría una nueva etapa en la ordenación educativa universitaria con el Real Decreto 1509/2005 que modifica los Reales Decretos 55/2005 y 56/2005 que regulan los estudios universitarios oficiales de grado y posgrado respectivamente ${ }^{35}$. El Real Decreto 1509/2005 sentaba las bases legales para que los títulos de Grado fueran creados por el Gobierno siguiendo unas exigencias generales, en cambio, los posgrados seguirían siendo competencia de las Universidades.

La Ley de Reforma Universitaria sufrió algunos cambios hasta la vigente LOU de 2001, modificada por la Ley Orgánica de $2007^{36}$. Ésta establece un título único fijado por el Gobierno y diferentes planes de estudios para obtener ese título, el cual, es determinado por las diversas Universidades. Así pues, el Ejecutivo fija cada título y sus características propias, señalando las materias troncales que deben figurar en todos los planes de estudios. De modo que cada Universidad redacta su propio plan de estudios para cada Grado incluyendo, obligatoriamente, esas materias troncales fijadas por el Gobierno junto con un número de materias que se pueden configurar libremente. Posteriormente, el Consejo de Coordinación Universitaria verifica ese plan de estudios $\mathrm{y}$, finalmente, deben ser autorizados en su implantación por la correspondiente Comunidad Autónoma (artículos 35 y ss. de la LOU). Sin embargo, las nuevas bases que sentó la LOU hizo necesario armonizar el sistema universitario al proceso de construcción del EEES. Con este objetivo nació el Real Decreto 1393/2007 que regula las enseñanzas universitarias y que ambiciona reforzar la autonomía universitaria al ser éstas las que crean y proponen, de acuerdo con las reglas establecidas, las enseñanzas y

como la nacionalidad; fecha de finalización de los estudios; lugar y fecha de expedición del título; firma de la persona interesada, del responsable de la unidad de títulos oficiales de la Universidad, y del Rector/a de la Universidad; mención de las causas legales que, en su caso, afecten a la eficacia del título; claves oficiales del título que se expide; y si procede, inclusión de la mención de "cum laude" así como de la mención "Doctor europeo".

${ }^{32}$ En relación a la expedición de títulos universitarios oficiales vid, además, la Resolución de 26 de junio de 1989, de la Secretaría de Estado de Universidades e Investigación, para la aplicación de lo dispuesto en las Ordenes de 8 de julio de 1988 y 24 de diciembre de 1988 en materia de títulos universitarios oficiales. [BOE núm. 170, de 18 de julio de 1989].

${ }^{33}$ Ley Orgánica 11/1983, de 25 de agosto, de Reforma Universitaria. [BOE núm. 209, de 1 de septiembre de 1983].

${ }^{34}$ FRAILE ARANDA, A. (2006), "El sistema universitario europeo como modelo posible para la educación superior latinoamericana”. Revista Electrónica de Investigación Educativa, n ${ }^{\circ}$ 1, vol. 8. [En línea] http://www .redalyc.org/articulo.oa?id=15508103.

${ }^{35}$ Real Decreto 1509/2005, de 16 de diciembre, por el que se modifican el Real Decreto 55/2005, de 21 de enero, por el que se establece la estructura de las enseñanzas universitarias y se regulan los estudios universitarios oficiales de grado y el Real Decreto 56/2005, de 21 de enero, por el que se regulan los estudios universitarios oficiales de posgrado. [BOE núm. 303, de 20 de diciembre de 2005].

${ }^{36}$ En relación a la evolución de la Universidad española desde la promulgación de la Ley de Reforma Universitaria hasta la actualidad vid, CALVO PÉREZ, B. y MICHAVILA PITARCH, F. (2000), La Universidad española hoy. Madrid: Fundación Alfonso Martín Escudero. 
títulos que han de impartir y expedir, sin sujeción a la existencia de un catálogo previo ${ }^{37}$ establecido por el Gobierno como hasta entonces ${ }^{38}$.

Pese a los cambios producidos, el concepto vertebral de 'título oficial' se ha mantenido inalterable ya sea el Gobierno o las Universidades quienes diseñen los estudios universitarios. No obstante, a raíz del Real Decreto 1393/2007 los títulos superiores adquieren diferentes tipologías: Graduado, Máster o Doctor ${ }^{39}$, frente a la anterior clasificación de Arquitecto, Ingeniero, Licenciado, Arquitecto Técnico, Ingeniero Técnico o Diplomado. Además, otra de las características fundamentales de los títulos universitarios españoles es la orientación que éstos pueden poseer, ya sea académica o profesional. La cuestión no es baladí, ya que el principio general es que el título dé acceso inmediato al ejercicio de una profesión sin más requisito que la colegiación, en su caso; aunque esta regla encuentra diversas excepciones.

Al efecto, con la llegada del EEES y la consiguiente adaptación de las titulaciones al nuevo plan educativo, se produjo la bifurcación orientativa de los distintos títulos de Grado. De manera que, en algunos casos, la obtención de un título de graduado habilita para el ejercicio profesional y, en otros, el título sólo tiene valor académico, siendo necesario la realización de un Máster para poder acceder a determinadas profesiones reguladas ${ }^{40}$, esto es, aquellas que sólo pueden realizarse cuando se cumplen los requisitos establecidos por ley. Por su parte, el título de Doctor habilita para la docencia y la investigación.

\footnotetext{
${ }^{37}$ El Catálogo de Títulos Universitarios Oficiales fue creado por la Disposición Adicional primera del Real Decreto 1497/1987, de 27 de noviembre, por el que se establecen directrices generales comunes de los planes de estudio de los títulos universitarios de carácter oficial y validez en todo el territorio nacional. [BOE núm. 298, de 14 de diciembre de 1987]. Y derogado por la reforma del proceso de Bolonia emprendida a partir de la publicación de la Ley Orgánica 6/2001, de 21 de diciembre, de Universidades, modificada por la Ley Orgánica 4/2007, de 12 de abril.

${ }^{38}$ Sobre la estructuración de los estudios universitarios a raíz del proceso de Bolonia sintetiza GARCÍAVELASCO GARCÍA, F.J. (2007), "El Proceso de Bolonia: situación actual", Revista de Derecho de la Unión Europea, no 12. [En línea] http://revistas.uned.es/index.php/REDUE/article/view/12497/11698.

${ }^{39}$ Artículo 8 del Real Decreto 1393/2007: "Las enseñanzas universitarias conducentes a la obtención de títulos de carácter oficial y validez en todo el territorio nacional se estructurarán en tres ciclos, denominados respectivamente Grado, Máster y Doctorado, de acuerdo con lo establecido en el artículo 37 de la Ley Orgánica 6/2001, de 21 de diciembre, de Universidades, en su nueva redacción dada por la Ley Orgánica 4/2007, de 12 de abril, por la que se modifica la anterior y en este real decreto".

40 Actualmente en España existen catorce profesiones que precisan de un título de Máster para poder ejercerlas. Entre las que se encuentran las de Abogado o Procurador de los Tribunales según dispone el Real Decreto 775/2011, de 3 de junio, por el que se aprueba el Reglamento de la Ley 34/2006, de 30 de octubre, sobre el acceso a las profesiones de Abogado y Procurador de los Tribunales; la de Arquitecto según establece la Orden EDU/2075/2010, de 29 de julio; Capitán y Jefe de máquinas de la Marina Mercante a raíz de lo dispuesto en el Real Decreto 973/2009, de 12 de junio, por el que se regulan las titulaciones profesionales de la marina mercante; Ingeniero aeronáutico en base a la Orden CIN/312/2009, de 9 de febrero; Ingeniero Agrónomo según la Orden CIN/325/2009, de 9 de febrero; Ingeniero de caminos, canales y puertos según se regula en la Orden CIN/309/2009, de 9 de febrero; Ingeniero de minas según la Orden CIN/310/2009, de 9 de febrero; Ingeniero de montes según la Orden CIN/326/2009, de 9 de febrero; Ingeniero de telecomunicación en base a la Orden CIN/355/2009, de 9 de febrero; Ingeniero industrial según la Orden CIN/311/2009, de 9 de febrero; Ingeniero naval y oceánico a raíz de la Orden CIN/354/2009, de 9 de febrero; Profesor de Educación Secundaria según la Orden ECI/3858/2007, de 27 de diciembre, y Orden EDU/3498/2011, de 16 de diciembre; y Psicólogo General Sanitario en base a la Orden ECD/1070/2013, de 12 de junio.
} 


\subsection{Efectos oficiales en España de los títulos universitarios extranjeros.}

A pesar de las diferentes reformas legislativas en la ordenación de los sistemas para dar validez a los títulos extranjeros en España hay un principio que se mantiene inalterable, y es que los títulos extranjeros carecen de efectos oficiales si no han sido previamente reconocidos por la autoridad española competente en virtud del procedimiento administrativo previsto para ello. Por tanto, para que un título académico foráneo pueda tener efectos oficiales hay que seguir una serie de trámites administrativos.

Los títulos universitarios españoles de carácter oficial y validez en todo el territorio nacional tienen efectos plenos tanto académicos como profesionales (artículo 4 del Real Decreto 1393/2007), desde la fecha de la completa finalización de los estudios correspondientes a su obtención (artículo 3.4 del Real Decreto 1002/2010) ${ }^{41}$. Así al referirnos a los efectos oficiales en el ámbito profesional hacemos alusión al ejercicio de una profesión regulada (abogado, procurador, etc.), cuyo desempeño exige estar en posesión de uno o dos títulos oficiales, los cuales, en su caso, habilitan para la realización de actividades profesionales reguladas. Por el contrario, si la profesión no se encuentra regulada, su ejercicio será totalmente libre, no siendo necesario título habilitante ni tampoco proceso de reconocimiento alguno de un título foráneo. Es decir, nada impide que un empresario español pueda contratar a una persona que posee un título extranjero que no ha sido sometido a ningún proceso de reconocimiento en España, ya que éste puede tomar en consideración el título de otro país que posea la persona, siempre y cuando la profesión no se encuentre regulada.

Otro de los efectos oficiales de los títulos es el académico, ya sea para el reconocimiento oficial de un nivel de estudios, titulación o para permitir a un extranjero continuar sus estudios oficiales en España. Esto incluye la convalidación de estudios extranjeros por estudios españoles superiores parciales para continuar estudiando en una Universidad de España, o bien, obtener la homologación a un título o la equivalencia a un nivel académico español para acceder a estudios de un nivel o ciclo superior.

Los efectos oficiales también afectan al acceso a la función pública. Tal y como recoge el ordenamiento jurídico español, los nacionales de los Estados miembros de la Unión Europea pueden acceder a la función pública en las mismas condiciones de igualdad que los nacionales españoles, según se establece la Ley del Estatuto Básico del Empleado Público $^{42}$ (artículo 57) y el Real Decreto 543/2001 ${ }^{43}$ sobre acceso al empleo público de nacionales de otros Estados miembros de la Unión Europea (art. 2 del Real Decreto $543 / 2001$ ); sin perjuicio de los cuerpos o escalas profesionales donde tal posibilidad se excluya expresamente (artículos 4 y 5 del Real Decreto 543/2001) ${ }^{44}$. En tal caso, habrá

\footnotetext{
${ }^{41}$ Vid, CARRILLO DONAIRE, J.A. (2007), La diferenciación jurídica entre títulos académicos y profesionales. II Congreso de la Asociación Española de Profesores de Derecho Administrativo. Santander: Universidad Internacional Menéndez Pelayo.

${ }^{42}$ Real Decreto Legislativo 5/2015, de 30 de octubre, por el que se aprueba el texto refundido de la Ley del Estatuto Básico del Empleado Público. [BOE núm. 261, de 31 de octubre de 2015].

${ }^{43}$ Real Decreto 543/2001, de 18 de mayo, sobre acceso al empleo público de la Administración General del Estado y sus Organismos públicos de nacionales de otros Estados a los que es de aplicación el derecho a la libre circulación de trabajadores. [BOE núm. 130, de 31 de marzo de 2001].

${ }^{44}$ Por otro lado, y en relación al acceso al mercado de trabajo de extranjeros no europeos en atención al derecho español de extranjería vid, CABALLERO GEA, J.A. (2005), Asilo. Extranjería, inmigración.
} 
que cumplir con los requisitos propios establecidos para el ingreso en el cuerpo o escala del que se trate (artículo 7 del Real Decreto 543/2001). Por tanto, el título extranjero del interesado tendrá que haber sido homologado o declarado equivalente al título o nivel académico español que permite el ingreso en un determinado cuerpo o escala.

Ahora bien, se prevén diversas excepciones al principio general de carencia de efectos oficiales en España de los títulos académicos extranjeros no homologados o declarados equivalentes por la autoridad competente española tales como las referidas al acceso a títulos oficiales de posgrado, sistemas de acreditación del profesorado o el acceso a estudios universitarios. En primer lugar, con respecto a la posibilidad de cursar estudios de tercer ciclo universitario, el Real Decreto 1393/2007 permite que las Universidades admitan para el acceso a estudios oficiales de posgrado, a titulados conforme a sistemas educativos extranjeros sin necesidad de la homologación de sus títulos, previa comprobación por la Universidad de que aquellos acreditan un nivel de formación equivalente a los correspondientes títulos universitarios oficiales españoles (artículo 16.2 del Real Decreto 1393/2007) ${ }^{45}$.

Asimismo, el Real Decreto $1312 / 2007^{46}$ que establece la acreditación para el acceso a los cuerpos docentes universitarios permite concurrir a la acreditación para el ingreso en el cuerpo de profesores titulares universitarios a candidatos con un título extranjero que no ha sido objeto de homologación en España (artículo 12.2 del Real Decreto 1312/2007), en tal caso, la obtención de la acreditación surtirá idénticos efectos que la homologación de dicho título ${ }^{47}$.

Junto a ello, la Ley Orgánica 2/2006 de Educación ${ }^{48}$ también prevé que los estudiantes de los diferentes Estados miembros de la Unión Europea o de Estados con los que se haya suscrito acuerdos internacionales puedan acceder a la Universidad española sin tener que realizar la correspondiente prueba de acceso, siempre y cuando el alumno

Homologación de títulos extranjeros. Nacionalidad. Síntesis y ordenación de la doctrina de los tribunales; Madrid: Dykinson; MOYA ESCUDERO, M. (2001), Comentario sistemático a la ley de extranjería. Granada: Comares y MOYA ESCUDERO, M. (1999), Los derechos de los trabajadores no comunitarios en España. Granada: Comares.

${ }^{45}$ Art. 16.2 del Real Decreto 1393/2007, de 29 de octubre, por el que se establece la ordenación de las enseñanzas universitarias oficiales: "podrán acceder los titulados conforme a sistemas educativos ajenos al Espacio Europeo de Educación Superior sin necesidad de la homologación de sus títulos, previa comprobación por la Universidad de que aquellos acreditan un nivel de formación equivalente a los correspondientes títulos universitarios oficiales españoles y que facultan en el país expedidor del título para el acceso a enseñanzas de postgrado". Dicha consideración también aparecía en el derogado Real Decreto 56/2005, de 21 de enero. E incluso el también derogado Real Decreto 778/1998, de 30 de abril, establecía de manera excepcional y con carácter discrecional por parte de la Universidad, que el interesado accediera a los estudios de Doctorado sin haber obtenido la homologación de su título en España, aunque, con esta forma de ingreso el título de Doctor que se obtenía en nuestro país carecía de los pertinentes efectos oficiales.

${ }^{46}$ Real Decreto $1312 / 2007$, de 5 de octubre, por el que se establece la acreditación nacional para el acceso a los cuerpos docentes universitarios. [BOE núm. 240, de 6 de octubre de 2007].

${ }^{47}$ Tal previsión se contemplaba en el derogado Real Decreto 338/2005 que modificaba el Real Decreto $774 / 2002$, de 26 de julio, por el que se regula el sistema de habilitación nacional para el acceso a cuerpos de funcionarios docentes universitarios y el régimen de los concursos de acceso respectivos. En su artículo 5.3 se permitía a los candidatos con títulos extranjeros oficiales no homologados o reconocidos concurrir a las pruebas de habilitación para ser profesor titular universitario.

${ }^{48}$ Ley Orgánica 2/2006, de 3 de mayo, de Educación. [BOE núm. 106, de 4 de mayo de 2006]. 
cumpla con los requisitos académicos exigidos en sus sistemas educativos para acceder a la Universidad (Disposición Adicional 33 de la Ley Orgánica 2/2006).

Sin embargo, como ya se ha mencionado anteriormente, estas son sólo excepciones de carácter legal al principio fundamental que vertebra la regulación del procedimiento de homologación, y figuras afines, en España, y, por el cual, los títulos extranjeros carecen de efectos oficiales en nuestro país sin el previo proceso para darles validez por la autoridad competente española.

\section{El régimen de homologación de títulos universitarios extranjeros en España y figuras afines.}

El actual sistema español para dar efectividad a los títulos universitarios extranjeros ha sido objeto de una importante evolución legislativa a lo largo de las últimas décadas. La regulación conducente a equiparar los estudios realizados en Universidades foráneas ha evolucionado desde un modelo clásico restrictivo hasta la regulación actual que se ha tornado más flexible.

Ya nos hemos referido al concepto actual de homologación entendiéndose por tal el reconocimiento oficial de la formación superada para la obtención de un título extranjero, equiparable a la exigida para la obtención de un título español que habilite para el ejercicio de una profesión regulada (art. 4.a) del Real Decreto 967/2014). De manera que la homologación sólo se reputa de aquellas profesiones españolas reguladas. No obstante, la homologación, así como sus distintas denominaciones en la legislación española, es un procedimiento de importante tradición en nuestro derecho interno. La primera referencia se localiza en la Ley de Instrucción Pública de 9 de septiembre de 1857 (promovida por Claudio Moyano, entonces Ministro de Fomento), en la que se abordaba el reconocimiento y la incorporación al ejercicio profesional ${ }^{49}$.

Posteriormente, se promulgaría el Decreto 190/1965 que reguló el acceso de titulados extranjeros a los estudios de Licenciatura y Doctorado. Le siguieron el Decreto 676/1969 y el Decreto 185/1985 que regulaban respectivamente la convalidación de títulos extranjeros y la homologación de títulos extranjeros y criterios relativos a la convalidación de los estudios de doctorado y postgraduados ${ }^{50}$.

\footnotetext{
${ }^{49}$ En el Título VI (“De los estudios hechos en país extranjero”) de la Ley de Instrucción Pública de 1857 se aborda el procedimiento de reconocimiento en España de los estudios realizados en una institución educativa no española. Para poder optar al reconocimiento era necesario, según se establecía a partir de su artículo 94, acreditar los cursos académicos realizados en el país extranjero, siempre que tuvieran "buena nota" según lo "requerido en nuestras Escuelas, y en igualdad de extensión y tiempo", en caso de no ser así, era necesario completar tal déficit con "las materias o el tiempo que faltaren". Además para cada incorporación era necesario "una autorización especial del Gobierno, que podrá concederla, oído el Real Consejo de Instrucción pública". No obstante, el Gobierno podía "por justas causas y oído el Real Consejo de Instrucción pública, conceder habilitación temporal para ejercer sus respectivas profesiones en los dominios españoles a los graduados extranjeros que lo solicitaren; siempre que acrediten la validez de sus títulos, haber ejercido su profesión por seis años, y pagado la cantidad que se les señale, la cual no podrá exceder de los derechos que se exijan por el mismo título en nuestros establecimientos".

${ }^{50}$ Decreto 190/1965, de 28 de enero, sobre regulación de los efectos de asistencia de Licenciados por Universidad no española a los cursos y estudios del Doctorado. Decreto 16761969, de 24 de julio, sobre convalidación de estudios y títulos extranjeros por los correspondientes españoles. Real Decreto 185/1985, de 23 de enero, por el que se regula el tercer ciclo de estudios universitarios, la obtención y expedición del título de Doctor y otros estudios postgraduados.
} 
Sin embargo, el presente artículo no pretende realizar un exhaustivo análisis de las raíces históricas sobre la ordenación de la materia objeto de estudio. En aras de concitar el mayor interés para el estudio de la cuestión se abordarán cada una de las normas que se han promulgado en los últimos treinta años para regular el procedimiento de homologación, y figuras afines, de títulos universitarios obtenidos en instituciones extranjeras, prestando especial atención al régimen jurídico vigente.

\subsection{Homologación de títulos extranjeros y las libertades comunitarias.}

Con la entrada en vigor de la Ley Orgánica de Reforma Universitaria de 1983 se hizo necesario el establecimiento de una norma de desarrollo para la homologación de títulos universitarios obtenidos fuera de nuestras fronteras ${ }^{51}$. Así nació el Real Decreto $86 / 1987^{52}$ que regulaba las condiciones de homologación de títulos universitarios extranjeros (vigente hasta el 4 de septiembre de 2004); el cual, armonizaba la dispersa normativa existente en la materia y la actualizaba a las diferentes disposiciones establecidas en la Ley de Reforma Universitaria. El Real Decreto estatal fijaba un único proceso de homologación, por un lado; y un proceso de convalidación de estudios, por otro. Con respecto al primero, la homologación, cuya autoridad competente era el Ministerio de Educación, sólo era posible con respecto a las titulaciones incluidas dentro de un catálogo cerrado de títulos.

A raíz de este Real Decreto, la homologación equiparaba el título extranjero con los mismos efectos académicos que el título español con el cual se homologaba ${ }^{53}$ (artículo 1 del Real Decreto 86/1987). Aunque en aquellos supuestos en que la formación acreditada no guardase equivalencia con la que proporcionaba el título español correspondiente se podía exigir la superación de unas pruebas sobre conocimientos básicos de la formación española requerida para obtener el título (artículo 2 del Real Decreto 86/1987) ${ }^{54}$. De forma que una solicitud de homologación podía obtener tres

\footnotetext{
${ }^{51}$ La Ley Orgánica de Reforma Universitaria se refiere a la homologación de títulos extranjeros en España en su artículo 32.2.

${ }^{52}$ Real Decreto 86/1987, de 16 de enero, por el que se regulan las condiciones de homologación de títulos extranjeros de educación superior.

${ }^{53}$ No obstante, tal proceso menguaba la posibilidad de homologar una titulación extranjera que carecía de acomodo claro e inequívoco con una determinada titulación española, ante lo cual, el interesado extranjero no podía ni siquiera obtener un reconocimiento general de su estatus de universitario.

${ }^{54}$ En este sentido, destaca la sentencia de la Audiencia Nacional de 13 de mayo de 2005 (Sala de lo Contencioso-Administrativo, Sección 1. ${ }^{a}$ ), recurso contencioso-administrativo núm. 153/2003, ponente: Sr. Diego Córdoba Castroverde. El recurso presentado tenía por objeto la impugnación de una resolución del Ministerio de Educación que denegaba a la recurrente la homologación de su título de Arquitectura, obtenido en la Universidad Javeriana de Colombia, al título español de Arquitecto. La normativa que afectaba a la cuestión, el Real Decreto 86/1987, señalaba que las resoluciones de concesión o denegación tomarán en consideración, en primer lugar, los Tratados o Convenios Internacionales, bilaterales o multilaterales en los que España sea parte. El Tribunal Supremo matizó que en estos casos la homologación no es automática, sino que exige que la Administración lleve un control de equivalencia del título extranjero respecto del español que se quiere homologar.

Y ese control administrativo es ejercido por la Comisión Académica del Consejo de Universidades, el órgano previsto por el Real Decreto 86/1987. En el caso enjuiciado este órgano informó desfavorablemente al considerar que la solicitud de la actora tenía carencias formativas en el título obtenido fuera de España, en relación con las materias troncales establecidas en el título español. No obstante, el Real Decreto 86/1987 también enumera, según establece la sentencia, como criterio
} 
respuestas del Ministerio de Educación: positiva, negativa o condicionada a la superación de una prueba de conjunto.

En relación a la convalidación sólo se contemplaba para estudios parciales. Mediante este procedimiento se permitía reconocer oficialmente la validez académica de los estudios universitarios realizados en el extranjero, hayan o no hayan concluido con la obtención de un título. De forma que el solicitante que hubiera obtenido la convalidación parcial de sus estudios universitarios podía seguir dicha formación en una Universidad española. La competencia correspondía a la Universidad de España en la que el interesado deseaba proseguir sus estudios, según los criterios fijados por el Consejo de Universidades. Por lo tanto y pese a que se suelen utilizar indistintamente, este Real Decreto diferenciaba entre homologación, por un lado, y convalidación, por otro. La homologación era a un título mientras que la convalidación se refería a estudios parciales.

Con este modelo clásico, la homologación sólo era posible entre los diferentes títulos de un catálogo cerrado. De manera que el Estado español, dentro del ámbito europeo, estaba vulnerando principios fundamentales del Derecho europeo en relación a los titulados universitarios procedentes de Estados miembros de la Unión Europa, tales como la libre circulación de los trabajadores ${ }^{55}$, el libre establecimiento ${ }^{56}$ y la no discriminación por razón de la nacionalidad del título ${ }^{57}$. De hecho, con tal situación, como detalla LOSTAO CRESPO "se estaban poniendo injustificadamente más trabas a los ciudadanos europeos de otras nacionalidades, que a los propios nacionales, ya que si a estos sólo se les pedía estar en posesión de un título universitario en términos generales, con independencia de la especialidad de este, no se debería haber exigido a los nacionales de otros países la homologación de su título universitario extranjero, porque era lo mismo que exigirles estar en posesión de una titulación determinada" ${ }^{58}$.

complementario a tomar en consideración en la homologación los precedentes administrativos aplicables al caso. Así que el órgano técnico que informa no pueden alejarse, sin motivación, de los criterios similares adoptados.

La recurrente abogó como término de comparación el expediente de homologación de otro solicitante que, también, se había licenciado en Arquitectura en la Universidad Javeriana de Colombia y al que la Administración, pese a apreciar carencias en su formación académica, consideró que no tenían suficiente entidad para denegarle la homologación, estableciendo la condición de superar una prueba de conjunto específica. De modo que del informe del Consejo de Coordinación Universitaria se desprende que no había razones para conferir un trato diferente a ambos solicitantes. Como consecuencia el acto impugnado se aparta injustificadamente de un precedente administrativo. De ahí que se otorgue a la recurrente el mismo tratamiento.

${ }^{55}$ Artículo 3.2 del Tratado de la Unión Europea (actual artículo 2.2 del vigente TUE); artículos 18, 39 y siguientes del Tratado Constitutivo de la Comunidad Europea (artículo 21 y títulos IV y V del actual Tratado de Funcionamiento de la Unión Europea) y artículo 45 de la Carta de los Derechos Fundamentales de la Unión Europea.

${ }^{56}$ Artículo 14 (mercado interior) del Tratado Constitutivo de la Comunidad Europea (artículo 26 del vigente Tratado de Funcionamiento de la Unión Europea); artículos 43 a 48 y 294 (establecimiento) del Tratado Constitutivo de la Comunidad Europea (actuales artículos 49 a 55 del Tratado de Funcionamiento de la Unión Europea) y artículos 49 a 55 (servicios) del TCE (actuales artículos 56 a 62 del Tratado de Funcionamiento de la Unión Europea).

${ }^{57}$ Artículo 21.1 de la Carta de los Derechos Fundamentales de la Unión Europea.

${ }^{58}$ LOSTAO CRESPO, F. (2016), "La homologación de títulos extranjeros en España, evolución del sistema y restricciones injustificadas", Revista electrónica del Departamento de Derecho de la 
De forma que si el título extranjero a homologar no encontraba acomodo en un determinada titulación española, el titulado foráneo se quedaba sin posibilidad de homologar su titulación y ni siquiera de reconocérsele su condición de universitario. Así se le estaba imposibilitando acceder a ciertos concursos públicos o formalizar determinadas modalidades contractuales (como por ejemplo un contrato de prácticas para universitarios).

En tal sentido, en el año 2002 la Comisión Europea elaboró una Comunicación titulada "Libre circulación de trabajadores - la plena realización de sus ventajas y sus posibilidades" 59 con el objetivo de informar a los ciudadanos de los derechos que le otorga el ordenamiento jurídico comunitario con respecto a la libre circulación y dar respuesta a las cuestiones más relevantes para los trabajadores migrantes ${ }^{60}$. No obstante, tal escrito dedica gran parte de su contenido a abordar el reconocimiento de las cualificaciones y títulos como factor esencial para permitir la movilidad de los trabajadores migrantes dentro de la Unión Europea. Así, tal comunicación establecía que "un ciudadano de un Estado miembro que esté plenamente cualificado para ejercer una profesión regulada (es decir, una profesión que no pueda practicarse sin unas cualificaciones profesionales determinadas) en un Estado miembro tiene derecho a que se reconozca su cualificación en otro Estado miembro". Por tanto, la Comisión Europea amparaba la idea de que la condición de universitario acreditada por una Universidad de un Estado miembro fuera respetada en el ámbito de la Unión Europea. Asimismo, tal documento también preveía "un período de adaptación", o bien, la realización de "una prueba de aptitud" si la formación o el campo de actividad de la profesión en cuestión era sustancialmente diferente en el Estado miembro de acogida. Sin embargo, no está de más recordar que las orientaciones y declaraciones del Consejo Europeo carecen de valor jurídico, teniendo tan sólo función orientativa en la vida política, económica o social.

\subsection{La homologación a un título o a un grado académico.}

El sistema universitario español experimentó profundos cambios en los años noventa, transformándose la vieja institución universitaria en un ente capaz de transmitir conocimientos científicos y tecnológicos. Para dar respuesta a las imperantes necesidades de la actividad universitaria y regular una nueva ordenación de ésta, se promulgó la Ley Orgánica 6/2001 de Universidades que derogaba la Ley de Reforma Universitaria de 1983. Según su Exposición de Motivos la renovada ley nacía con el

\footnotetext{
Universidad de La Rioja, $\mathrm{n}^{\mathrm{o}} \quad 14, \quad$ p. $\quad 88 . \quad$ [En $\quad$ línea] http://www.unirioja.es/dptos/dd/redur/numero14/lostao.pdf.

${ }^{59}$ Unión Europea. Comunicación de la Comisión Europea. "Libre circulación de trabajadores y la plena realización de sus ventajas y sus posibilidades", 11 de diciembre de 2004. [En línea] https://www.cgcom.es/sites/default/files/boletin_95_com2002_0694.pdf.

${ }^{60}$ La comunicación se centra en la reiterada jurisprudencia del Tribunal de Justicia de la Unión Europea sobre la libre circulación de trabajadores, así como el derecho de todo europeo a vivir y trabajar en otro Estado miembro. En concreto, repara en diversas cuestiones que se encuentran relacionadas entre sí y que suponen un obstáculo para el ciudadano, entre las que se localizan el acceso al empleo, los requisitos de conocimiento del idioma del país de destino, la igualdad de trato y las ventajas sociales, los problemas administrativos y jurídicos relacionados con los derechos de residencia, los trabajadores fronterizos, el acceso a puestos de trabajo en el sector público y las prestaciones de seguridad social y asistencia sanitaria en otro Estado miembro.
} 
objeto de optimizar la normativa de Universidades para "mejorar su calidad docente, investigadora y de gestión; fomentar la movilidad de estudiantes y profesores [...]". A su vez, el artículo 36.2.b) de la LOU de 2001 señalaba que el Gobierno regulará, previo informe del Consejo de Coordinación Universitaria, las condiciones de homologación de títulos extranjeros de educación superior. Tal materia se había regido hasta la fecha por el Real Decreto 86/1987, que estuvo en vigor diecisiete años. Sin embargo era necesario adaptarla al nuevo contexto social, normativo y educativo. Así se promulgó el Real Decreto 285/2004 para la homologación y convalidación de títulos y estudios extranjeros universitarios (vigente hasta el 23 de noviembre de 2014) y modificado un año después ${ }^{61}$.

El Real Decreto 285/2004 que desarrollaba la LOU de 2001 pretendía adecuar la materia objeto de regulación a un nuevo entorno radicalmente distinto del contemplado en el anterior Real Decreto sobre homologación de finales de los años ochenta. La plena incorporación de España a la Unión Europea propició la necesidad de una nueva legislación en materia de reconocimiento de títulos universitarios acordes con los tiempos. Pero sobre todo, la Declaración de Bolonia y la LOU de 2001 instauraron un nuevo contexto de modificación de la normativa reguladora de la educación superior que afectó al procedimiento de homologación de títulos universitarios foráneos. Junto a ello también es preciso tener en cuenta el contexto social de aquellos momentos, ya que España se convirtió en un importante foco de atracción de población extranjera y esto se tradujo en un significativo aumento del número de solicitudes de homologación de títulos universitarios de otros países. En los tres años posteriores a la entrada en vigor de esta norma, el Ministerio español de Educación recibió más de 72.000 nuevas solicitudes de homologación ${ }^{62}$.

Al efecto, el Real Decreto 285/2004 diferenciaba entre dos procedimientos: la homologación a un título universitario oficial o a un grado académico y la convalidación de estudios parciales ${ }^{63}$. Con respecto a la homologación, la norma establecía dos posibilidades: la homologación a un título concreto (artículo 1. a) del Real Decreto 285/2004) o la homologación a un grado académico genérico (artículo 1. b) del Real Decreto 285/2004). En relación a la primera, se reconocía oficialmente la formación superada para la obtención de un título extranjero como equivalente al que se exige en España para obtener un título dentro de los incluidos en el catálogo oficial. En relación a la segunda, se propugnaba el reconocimiento de la formación superada para

\footnotetext{
${ }^{61}$ Real Decreto 285/2004, de 20 de febrero, por el que se regulaban las condiciones de homologación y convalidación de títulos y estudios extranjeros de educación superior. [BOE núm. 55, de 4 de marzo de 2004]. Modificado por el Real Decreto 309/2005, de 18 de marzo. La norma introduce como novedad la competencia de los Rectores de las Universidades para homologar títulos extranjeros a los títulos y grados académicos al título y grado de Doctor, a los nuevos títulos oficiales de Máster (que establecía el derogado Real Decreto 56/2005) y al grado académico de Máster.

${ }^{62}$ VÁZQUEZ-REINA, M. "Homologar el grado de un título universitario extranjero". Consumer.es. 7 de febrero de 2008.2 [En línea] http://www.consumer.es/web/es/educacion/universidad/2008/02/07/174381.php.

${ }^{63}$ Sobre el procedimiento administrativo concreto vid, PÉREZ DEL BLANCO, G. (2005), "Estructura y titulaciones de Educación Superior en España", Proyecto sobre Homologación y reconocimiento de títulos de educación superior en Iberoamérica. Organización de Estados Iberoamericanos, OEI. [En línea] www.oei.es/historico/homologaciones/espana.pdf.
} 
la obtención de un título extranjero como equivalente a la exigida para la obtención de un grado académico a cualquiera de los niveles en los que se estructuraban los estudios universitarios, en vez de a un título concreto. Es decir, se homologaba el grado académico de Diplomado Universitario, Arquitecto Técnico, Ingeniero Técnico, Licenciado, Arquitecto, Ingeniero y Doctor pero no el título concreto; de manera que no se podía acceder a una profesión regulada que exigiera un título determinado. Por último, de manera residual también se establecía la posibilidad de convalidar estudios extranjeros por estudios parciales universitarios españoles (artículo 1.c) del Real Decreto 285/2004).

A diferencia de las insuficiencias que presentaba la anterior regulación, en esta ocasión el procedimiento diseñado no se contemplaba como una absoluta identidad en cuanto a las denominaciones o contenidos de los programas formativos sino como una equiparación entre los estudios acreditados por el título extranjero y los que podrían ser el correspondiente español. Así, se articulaba un proceso que posibilitaba no sólo declarar la homologación a un título de los insertos en el catálogo oficial (Capítulo II, Sección 1. a del Real Decreto 285/2004) como ya ocurría anteriormente, sino a un grado académico (Capítulo II, Sección 2. ${ }^{a}$ del Real Decreto 285/2004) de los previstos en el artículo 37 de la LOU de 2001, la cual, regulaba la estructura y organización de las enseñanzas universitarias en tres ciclos cuya superación daba lugar a los mencionados títulos de Diplomado Universitario, Arquitecto Técnico, Ingeniero Técnico, Licenciado, Arquitecto, Ingeniero y Doctor. La competencia correspondía al Ministerio de Educación, excepto en el caso de la homologación del título de Doctor, cuya autoridad competente eran las Universidades. La resolución adoptada por el Ministerio para la homologación a un título universitario podía contener los siguientes pronunciamientos: positivo, negativo o condicionado a la superación de unos requisitos complementarios. En cambio para la homologación a nivel académico sólo sería positiva o negativa.

Así pues, la homologación de título universitario o grado académico se reputaba de los títulos extranjeros de educación superior ya sea título, certificado o diploma con validez oficial, acreditativo de la completa superación del correspondiente ciclo de estudios superiores, incluido, en su caso, el período de prácticas necesario para su obtención, expedido por la autoridad competente de acuerdo con la legislación del Estado al que pertenezcan dichos estudios (artículo 3. d) del Real Decreto 285/2004). Además, los títulos debían de reunir una serie de requisitos (artículo 19 del Real Decreto 285/2004).

De este modo hubo que esperar hasta el año 2004 para que el Estado español reconociera la condición genérica de universitario y posibilitara un nuevo modelo de homologación en base al grado académico del solicitante ${ }^{64}$. Además con esta norma el legislador trataba de adaptarse a los principios fundamentales del Derecho europeo y adecuar el procedimiento planteado a las exigencias y directrices emanadas de las instituciones europeas, en cuanto al ámbito de la libertad de establecimiento, de prestación de servicios y de la movilidad de los trabajadores y profesionales de los Estados miembros de la Unión Europea.

\footnotetext{
${ }^{64}$ Con el anterior Real Decreto 86/1987, de 16 de enero, por el que se regulan las condiciones de homologación de títulos extranjeros de educación superior, se imposibilitaba homologar una titulación extranjera sin acomodo claro con una determinada titulación española y el interesado extranjero no podía obtener ni siquiera la condición general de universitario.
} 
Por último, para la convalidación de estudios extranjeros por estudios universitarios españoles parciales (Capítulo III del Real Decreto 285/2004) la competencia recaía en la Universidad de España donde el interesado pretendiera seguir sus estudios (artículo 23 del Real Decreto 285/2004), de acuerdo con los criterios fijados por el Consejo de Coordinación Universitaria ${ }^{65}$.

\subsection{El actual marco jurídico de la homologación: distinción de figuras afines.}

\subsubsection{La homologación, declaración de equivalencia y convalidación.}

Tras más de cinco años desde que fue promulgada la LOU de 2001 ésta presentaba algunas deficiencias en su funcionamiento que aconsejaban una revisión. El contexto en el que nació la norma había sufrido importantes modificaciones con la construcción del Espacio Europeo de Educación Superior y el impulso de la Unión Europea a la investigación en todos sus países miembros. Estos aspectos hicieron necesario una nueva norma adaptada a las circunstancias. Así, la LOU de 2001 fue modificada por la Ley Orgánica 4/2007. La norma realizó una importante reforma en la estructura y organización de las enseñanzas universitarias, basada en tres ciclos: Grado, Máster y Doctorado $^{66}$, con el objetivo de lograr la armonización de los sistemas educativos superiores en el marco del EEES y supuso la desaparición del catálogo de títulos universitarios oficiales. Según se desprende de la Exposición de Motivos de la actual LOU se intenta asentar "los principios de un espacio común, basado en la movilidad, el reconocimiento de titulaciones y la formación a lo largo de la vida". A partir de tal norma legal las Universidades ostentan la competencia para crear, según las reglas

\footnotetext{
${ }^{65}$ En este sentido, destaca la sentencia de la Audiencia Nacional de 18 de febrero de 2009 (Sala de lo Contencioso-Administrativo, Sección 3.a); recurso contencioso-administrativo 273/2007; ponente: Sr. Diego Córdoba Castroverde. El recurso presentado se basaba en una resolución del Ministerio de Educación que denegaba la solicitud de homologación del título de Bachelor of Arts in Business Studies with Tourism obtenido en una Universidad del Reino Unidos, al título de Licenciado en Administración y Dirección de Empresa. La resolución denegó la homologación al considerar que los estudios realizados por la recurrente en el extranjero se enmarcan en el Programa Erasmus mediante un acuerdo de doble titulación de la Universidad de las Islas Baleares, considerando que los estudios cursados bajo dicho programa solo pueden ser objeto de convalidación por las Universidades parte en dicho acuerdo, pero no objeto de homologación.

El Real Decreto 285/2004 consideraba que para la aplicación del procedimiento de homologación era necesario que el título invocado sea susceptible de equiparación a los que tienen en España carácter oficial, quedando excluidos los que no tengan tal carácter que solo podrían ser reconocidos recíprocamente entre Universidades. Así, la homologación recae sobre los títulos y el carácter oficial se proyecta sobre los mismos y no sobre los estudios.

Consecuencia de ello, la homologación de un título oficial extranjero no podía denegarse por el hecho de que los estudios sean de un programa de intercambio de alumnos entre Universidades, pues lo esencial es que los títulos hayan sido expedidos con ese carácter oficial en el país de origen. Son las autoridades de ese Estado quienes tienen que valorar si los estudios cursados, según su ordenamiento jurídico interno, atribuyen al título el carácter de oficial, aspecto sobre el que no tiene competencia el país receptor. Por todo ello, el acto recurrido debió comprobar si el título expedido en el Reino Unido tenía carácter oficial, o si se trataba de un título propio de la Universidad inglesa que, como ocurre con el título de la Universidad balear, no es oficial, tramitar el procedimiento y realizar el pertinente juicio de equivalencia sobre duración y contenidos con el equivalente español. Como no se actuó en tal sentido, se estimó el recurso y se anuló la resolución recurrida, retrotrayendo las actuaciones al momento de la solicitud inicial para que se iniciara y se tramitará según lo establecido en el Real Decreto 285/2004.

${ }^{66}$ La LOU de 2001 estructuraba las enseñanzas universitarias en títulos de Diplomado Universitario, Arquitecto Técnico, Ingeniero Técnico, Licenciado, Arquitecto, Ingeniero y Doctor (artículo 37).
} 
establecidas, las enseñanzas y títulos que imparten y expiden, sin sujeción a un catálogo previo fijado por el Gobierno. Ahora, los títulos que diseñen las Universidades deben reflejar la descripción de los contenidos formativos y la adquisición de competencias por parte de los estudiantes.

La nueva ordenación de la educación universitaria prevé títulos que habilitan para el acceso o el ejercicio de actividades profesionales reguladas, cuyos planes de estudio deben sujetarse a las condiciones establecidas por el Ejecutivo para garantizar que los títulos acreditan la posesión de las competencias para ejercer la profesión. De manera que se hace patente la doble vertiente que pueden tener los títulos universitarios, los habilitantes para el ejercicio de profesiones reguladas y los que carecen de tal condición.

Partiendo de lo dispuesto en el artículo 36 de la LOU, tras su reforma de 2007, que atribuye al Gobierno, previo informe del Consejo de Universidades, el establecimiento de los criterios generales a los que deberán ajustarse las universidades en materia de convalidación y adaptación de estudios cursados en centros extranjeros y las condiciones de homologación de títulos extranjeros, se hizo preciso un procedimiento para el reconocimiento de títulos universitarios extranjeros que tuviera presente la nueva realidad del sistema universitario español. Así, se promulga el Real Decreto 967/2014 ${ }^{67}$ que desarrolló la vigente LOU. El citado Real Decreto propugna un procedimiento de carácter universal válido para un título universitario oficial procedente de cualquier sistema educativo del mundo, con independencia de la nacionalidad de la persona que lo haya cursado. Mediante una comparación de ambas formaciones, la poseída por el solicitante frente a la que se quiere homologar o equivaler, se atribuye al título extranjero todos los efectos del título español con el cual se homologa o se declara equivalente.

El Real Decreto diferencia entre tres tipos de procedimientos: la homologación, la declaración de equivalencia y la convalidación (aunque la norma se estructura en función de las dos primeras). Con respecto al primero, se dispone la homologación de un título extranjero a un título universitario español que dé acceso a una profesión regulada en España. De forma que tal denominación se reserva exclusivamente a los títulos habilitantes para el ejercicio de profesiones reguladas ${ }^{68}$, tomando en

\footnotetext{
${ }^{67}$ Real Decreto 967/2014, de 21 de noviembre, por el que se establecen los requisitos y el procedimiento para la homologación y declaración de equivalencia a titulación y a nivel académico universitario oficial y para la convalidación de estudios extranjeros de educación superior, y el procedimiento para determinar la correspondencia a los niveles del marco español de cualificaciones para la educación superior de los títulos oficiales de Arquitecto, Ingeniero, Licenciado, Arquitecto Técnico, Ingeniero Técnico y Diplomado. [BOE núm. 283, de 22/11/2014].

${ }^{68}$ En el Anexo I del Real Decreto $967 / 2014$ se recogen las titulaciones que habilitan para el ejercicio de profesiones reguladas: Abogado, Procurador, Médico, Veterinario, Enfermero, Enfermero, Dentista, Farmacéutico, Logopeda, Óptico-Optometrista, Podólogo, Terapeuta Ocupacional, Dietista Nutricionista, Psicólogo General Sanitario, Ingeniero de Caminos, Canales y Puertos, Ingeniero de Minas, Ingeniero Industrial, Ingeniero Aeronáutico, Ingeniero Agrónomo, Ingeniero de Montes, Ingeniero Naval y Oceánico, Ingeniero de Telecomunicación, Arquitecto, Ingeniero Técnico de Minas, Ingeniero Técnico de Obras Públicas, Ingeniero Técnico Aeronáutico, Ingeniero Técnico Agrícola, Ingeniero Técnico Forestal , Ingeniero Técnico Naval, Ingeniero Técnico Industrial, Ingeniero Técnico de Telecomunicación, Ingeniero Técnico en Topografía, Arquitecto Técnico, Maestro en Educación Infantil, Maestro en
} 
consideración la normativa por la que se establecen los requisitos de verificación de los títulos universitarios oficiales que habiliten para el ejercicio de las profesiones correspondientes. Con relación a la declaración de equivalencia de un título extranjero ésta se establece para el resto de los supuestos, es decir, para las titulaciones que no habilitan para el acceso a una profesión regulada ${ }^{69}$. Con dicho procedimiento se establece la posibilidad de obtener la equivalencia a nivel académico y a la titulación correspondiente a un área y campo específico en los que pueden agruparse los diferentes títulos universitarios. Así, se contempla un sistema de referencias con una serie de requisitos que deben cumplirse: ser compatible con la normativa española y al mismo tiempo, reconocido y compartido internacionalmente; adaptarse a los diversos contextos de educación superior; y dar lugar a una adscripción clara y objetiva por parte de la titulación de origen al ámbito disciplinar de pertenencia. En definitiva, esta nueva figura viene a sustituir la denominada homologación de nivel o grado que instauró el anterior Real Decreto 285/2004 en su artículo 18 y que pretendía otorgar un nivel universitario a los titulados extranjeros que estaban en posesión de una titulación que no encontraba acomodo con las existentes en el catálogo oficial. El procedimiento de equivalencia difiere según vaya referido a una titulación de Grado o Máster, o bien, al título de Doctor (Disposición Adicional Quinta del Real Decreto 967/2014). En el Anexo II del Real Decreto 967/2014 se localizan las ramas de conocimiento y los campos susceptibles de declaración de equivalencia (Artes y humanidades, Ciencias Sociales y Jurídicas, Ciencias, Ingeniería y Arquitectura y Ciencias de la Salud). No obstante, los escasos ámbitos de conocimientos que figuran en el mencionado Anexo pueden llegar a producir cierta imprecisión, ya que algunas de las ramas son demasiado amplias o ambiguas. Por ejemplo, el campo de Humanidades resulta bastante extenso; en el caso de ciertos estudios como marketing, publicidad o relaciones públicas encuentran difícil encaje en el campo genérico de Ciencias Sociales y Jurídicas.

Por último, la convalidación supone el reconocimiento de períodos de estudios extranjeros de educación superior por los correspondientes españoles de acuerdo con la nueva estructura de formación universitaria (artículo 4 del Real Decreto 967/2014).

Frente a la anterior regulación que ampliaba el concepto de homologación al permitir homologar no sólo con respecto a un determinado título del catálogo oficial sino también a un grado académico ${ }^{70}$, el vigente Real Decreto 967/2014 limita el ámbito de aplicación del procedimiento de homologación, lo cual, ha sido calificado por algunos autores como una atribución para "privilegiar" determinadas titulaciones ${ }^{71}$, ya que en la anterior regulación el término homologación se extendía enormemente, a diferencia de lo que ocurre ahora con el Real Decreto 967/2014, donde tal concepto sólo se reputa con respecto a títulos habilitantes para profesiones reguladas.

\footnotetext{
Educación Primaria y Profesor de Educación Secundaria Obligatoria y Bachillerato, Formación Profesional y Enseñanzas de Idiomas.

${ }^{69}$ El Anexo II del Real Decreto 967/2014 relaciona las ramas de conocimiento y los campos susceptibles de declaración de equivalencia.

${ }^{70}$ Capítulo II, Sección 1. a y 2. a del Real Decreto 285/2004, de 20 de febrero, por el que se regulan las condiciones de homologación y convalidación de títulos y estudios extranjeros de educación superior.

${ }^{71}$ LOSTAO CRESPO, F. Op. cit., p. 93.
} 
Con la nueva norma, la vía del reconocimiento profesional se remite a su normativa específica (Disposición Adicional Tercera del Real Decreto 967/2014) ${ }^{72}$. Figura jurídica que no debe confundirse con la homologación que regula el mismo Real Decreto 967/2014. Así, los solicitantes nacionales de Estados miembros de la Unión Europea, Espacio Económico Europeo o Suiza que quieran ejercer una profesión regulada en España a la que se acceda mediante la obtención de títulos de nivel universitario, si dichos títulos han sido expedidos o reconocidos en alguno de estos países o espacios europeos (UE, EEE o Suiza), pueden solicitar el reconocimiento profesional según la Directiva 2005/36/CE. Mediante tal procedimiento el interesado podrá ejercer una profesión regulada en España pero no tiene efectos académicos. Este procedimiento es compatible tanto con el procedimiento de homologación como con el de equivalencia. LOSTAO CRESPO sostiene que "aunque es cierto que se trata de instituciones reguladas por normativas distintas, y con alcance distinto (la homologación más completo y el reconocimiento profesional más limitado), también lo es que en España ya estaba consolidada la vía del reconocimiento para la actividad profesional, y el introducir ahora una homologación con efectos profesionales y académicos a la vez, se puede generar confusión"”73.

Por último, con el nuevo Real Decreto entra en escena la Agencia Nacional de Evaluación y Calidad de la Acreditación (ANECA) ${ }^{74}$ encargada del examen y valoración de las antiguas titulaciones y cuya función principal es verificar los títulos actuales y las competencias que se adquieren al obtener tal documento ${ }^{75}$.

\subsubsection{Procedimiento de correspondencia a nivel MECES para favorecer la movilidad en el extranjero.}

El Espacio Europeo de Educación Superior trajo consigo la necesidad de definir un régimen general de correspondencia a un nivel del Marco Español de Cualificaciones para la Educación Superior (MECES) de los títulos anteriores a la reforma de Bolonia ${ }^{76}$, ya que desde la desaparición, en el año 2007, del catálogo oficial de títulos

\footnotetext{
${ }^{72}$ Regulado en el Real Decreto 1837/2008, de 8 de noviembre, por el que se incorporan al ordenamiento jurídico español la Directiva 2005/36/CE, del Parlamento Europeo y del Consejo, de 7 de septiembre de 2005, y la Directiva 2006/100/CE, del Consejo, de 20 de noviembre de 2006; relativas al reconocimiento de cualificaciones profesionales, así como a determinados aspectos del ejercicio de la profesión de abogado. [BOE núm. 280, de 20 de noviembre de 2008]. Dicha norma establece las reglas para permitir el acceso y ejercicio de una profesión regulada en España, mediante el reconocimiento de las cualificaciones profesionales adquiridas en otro u otros Estados miembros de la Unión Europea y que permitan a su titular ejercer en él la misma profesión.

${ }^{73}$ LOSTAO CRESPO, F. Op. cit., p. 95.

${ }^{74}$ Creada por el Real Decreto 1052/2002, de 11 de octubre, por el que se regula el procedimiento para la obtención de la evaluación de la Agencia Nacional de Evaluación de la Calidad y Acreditación, y de su certificación, a los efectos de contratación de personal docente e investigador universitario. [BOE núm. 245, de 12 de octubre de 2002].

${ }^{75}$ DEL CAMPO, S., MUÑOZ, E., BERZOSA, C., COTARELO, R., RUBIO LARA, J.M., LAPORTA, F., MYRO, R., Y SOLÉ, C. (2013), "La ANECA y la crisis de la Universidad Española", Temas para el Debate, $\mathrm{n}^{\circ} 229$, pp. 42-49.

${ }^{76}$ La Disposición Adicional Cuarta del Real Decreto 1393/2007, de 29 de octubre, por el que se establece la ordenación de las enseñanzas universitarias oficiales, dispuso, que los títulos obtenidos conforme a los anteriores planes de estudio mantendrían sus efectos académicos y profesionales.
} 
universitarios $^{77}$ existía un vacío que el Real Decreto 967/2014 vino a solucionar. Por ello, junto con el procedimiento para la homologación y declaración de equivalencia a titulación y a nivel académico universitario oficial y para la convalidación de estudios extranjeros de educación superior, el Real Decreto 967/2014 también regula el procedimiento para determinar la correspondencia a los niveles del marco español de cualificaciones para la educación superior de los títulos oficiales de Arquitecto, Ingeniero, Licenciado, Arquitecto Técnico, Ingeniero Técnico y Diplomado. Por tanto, el texto normativo diferencia entre, por un lado, los procedimientos de homologación y sus figuras afines y por otro, la correspondencia a nivel MECES.

El Marco Español de Cualificaciones para la Educación Superior proporciona una tabla que permite clasificar y comparar las titulaciones universitarias españolas pre-Bolonia para así obtener un certificado de correspondencia ${ }^{78}$ de un título de Arquitecto, Ingeniero, Licenciado, Arquitecto Técnico, Ingeniero Técnico o Diplomado a los niveles MECES ${ }^{79}$. Con ello, se pretende facilitar la movilidad en el extranjero de los titulados universitarios españoles con un título anterior a la reforma de la educación superior y, de este modo, no crear desventajas en estos egresados con respectos a los titulados conforme al nuevo Espacio de Europeo de Educación Superior ${ }^{80}$. Pero tal procedimiento sólo es válido para los títulos oficiales expedidos por las Universidades, no para los títulos propios (artículo 2.4 del Real Decreto 967/2014).

Todo el procedimiento para determinar la correspondencia de los títulos oficiales a nivel MECES aparece regulado en el Capítulo III del Real Decreto 967/2014, y es detallado en el epígrafe quinto de este documento. Para optar a él, el interesado debe estar en posesión de un título universitario oficial español de Arquitecto, Ingeniero, Licenciado, Arquitecto Técnico, Ingeniero Técnico y Diplomado cuya correspondencia con un nivel MECES haya sido aprobada mediante Acuerdo de Consejo de Ministros, publicada en Boletín Oficial del Estado e inscrita en el Registro de Universidades, Centros y Títulos (RUCT) ${ }^{81}$. De manera que las personas que hayan obtenido un título en España antes de

\footnotetext{
77 A raíz de la promulgación de la Ley Orgánica 6/2001 de Universidades, modificada por la Ley Orgánica 4/2007 de 12 de abril, que adaptó el sistema universitario español al Espacio de Europeo de Educación Superior.

${ }^{78}$ La Sentencia del Tribunal Superior de Justicia de Navarra de 9 de mayo de 2017 (Sala de lo Contencioso-Administrativo, Sección 1 1ª), recurso contencioso-administrativo núm. 75/2017, ponente: Sra. María de las Mercedes Martin Olivera; aclara el concepto de 'correspondencia', entendiendo, que tal término "no debe confundirse con una equiparación", ésta "consiste en una aclaración destinada sobre todo al ámbito europeo". Y aclara que su finalidad es "evitar cualquier tipo de confusión fuera de España, para que quienes hicieron la carrera con planes de estudio antiguos no tengan problemas a la hora de trabajar en otros países".

${ }^{79}$ En concreto, el Real Decreto 1027/2011, de 15 de julio, por el que se establece el Marco Español de Cualificaciones para la Educación Superior, establece cuatro niveles de cualificación en función de los resultados de aprendizaje que proporcionan los estudios oficiales: el nivel de Técnico Superior se incluye en el Nivel 1, el de Grado en el Nivel 2, el de Máster en el Nivel 3, y el de Doctor en el Nivel 4.

${ }^{80}$ Vid, Sentencia del Tribunal Supremo de 1 de junio de 2017 (Sala de lo Contencioso-Administrativo, Sección $4^{\circ}$ ). Recurso de Casación núm. 4099/2015. Ponente: Sr. Rafael Toledano Cantero.

${ }^{81}$ La correspondencias a nivel MECES de las titulaciones universitarias españolas oficiales se pueden consultar en la propia web del Ministerio de Educación (https://www.mecd.gob.es/servicios-alciudadano-mecd/catalogo/general/educacion/202058/ficha/202058.html), la cual, publica los diferentes acuerdos que el Consejo de Ministros que ratifican el nivel de cada una de las 140 titulaciones de educación superior en España antes de la llegada del proceso de Bolonia.
} 
la implantación del proceso de Bolonia podrán recurrir al procedimiento habilitado para declarar la correspondencia de sus títulos a los niveles del Marco Europeo de Educación Superior ${ }^{82}$.

\subsubsection{Características formativas y causas de exclusión para la homologación de títulos extranjeros y figuras afines.}

El vigente Real Decreto 967/2014 enuncia las causas de exclusión (artículo 3 del Real Decreto 967/2014) y los criterios de homologación y declaración de equivalencia (artículo 10 del Real Decreto 967/2014), cuya redacción es prácticamente idéntica a la contenida en el anterior Real Decreto 285/2004 ${ }^{83}$; y además, incorpora los requisitos de formación que deben tener los títulos universitarios extranjeros susceptibles de homologación o declaración de equivalencia (artículo 7 del Real Decreto 967/2014). Por primera vez, la regulación de tal materia enumera las características formativas que deben poseer los títulos superiores extranjeros para poder ser homologados o declarados equivalente.

Al efecto, los títulos de formación extranjeros susceptibles de ser homologados o de declarados equivalentes deberán cumplir una serie de condiciones. En primer lugar, el título extranjero tiene que haber sido expedido oficialmente (artículo 7.1.a) del Real Decreto 967/2014). De manera que para proceder a homologar o equivaler un título obtenido en una Universidad extranjera, éste tiene que haber sido expedido por una autoridad oficial en el país expedidor según su propio ordenamiento jurídico. El segundo requisito hace referencia a las exigencias de acceso, ya que el poseedor debe acreditar que cumple los requisitos de nivel exigidos en España para acceder a un Grado o Máster (artículo 7.1. b) del Real Decreto 967/2014) ${ }^{84}$. El tercer requisito es la

\footnotetext{
${ }^{82}$ En este sentido es interesante comprobar las reivindicaciones de la Conferencia de Decanos de Geológicas de España ante la promulgación del Real Decreto 967/2014 en relación al procedimiento de correspondencia al nivel MECES. Vid, SUÁREZ ORDÓÑEZ, L.E. (2015), "Los retos de la profesión de geólogo ante la nueva legislación de títulos universitarios y profesionales", Tierra y tecnología: revista de información geológica, $\mathrm{n}^{\mathrm{o}}$ 46. [En línea] http://www.aufop.com/aufop/revistas/indice/digital/178. Asimismo, vid, el informe emitido por la ANECA con el objeto de estudiar la correspondencia del título oficial de Ingeniero Geólogo con los niveles del Marco Español de Cualificaciones de la Enseñanza Superior. [En línea] https://www.mecd.gob.es/servicios-al-ciudadano-mecd/dms/mecd/servicios-alciudadano-mecd/informacion-publica/audiencia-informacion-publica/cerrados/2015/correspondencianivel-meces-20150801/34-ingeniero-geologo/eq58-if-ingeniero-geologo-19062015.pdf.

${ }^{83}$ El derogado Real Decreto 285/2004 regulaba las causas de exclusión en su artículo 5 y los criterios necesarios para la homologación en su artículo 9.

${ }^{84}$ Este requisito guarda gran semejanza al criterio de homologación y declaración de equivalencia recogido en el artículo 10.1.a) del mismo Real Decreto 967/2014. Para LOSTAO CRESPO, F. Op. cit., p. 96. "La introducción de este requisito del título, por esta vía, que también está incluido como criterio de homologación, parece pretender sortear lo dispuesto en el art. 10. 4 del nuevo Real Decreto de homologaciones, que se refiere específicamente a la homologación de títulos europeos". El mencionado artículo 10.4, impone requisitos específicos para la equivalencia a nivel académico de Grado y Máster cuando se solicite para un título procedente de la Unión Europea, EEE y Suiza. Si el título ha sido obtenido en algunos de estos espacios, la resolución de declaración de equivalencia a titulación y a nivel académico solo tendrá en cuenta únicamente los criterios del artículo 10.1.c). Así, los criterios para la equivalencia a titulación y a nivel académico de titulaciones de educación superior de la Unión Europea, el Espacio Económico Europeo y Suiza son menos taxativas que para el resto, por lo que "pudiera parecer que lo que se pretende por esta nueva vía de los requisitos del títulos, es darle la vuelta al asunto, y poder
} 
superación de un ciclo completo de estudios: Grado o Máster (artículo 7.1.c del Real Decreto 967/2014). El cuarto requisito se refiere a las competencias formativas, las cuales, hay que acreditar que se han obtenido (artículo 7.1. d) del Real Decreto 967/2014). Como ha señalado LOSTAO CRESPO este requisito, que se incluye por primera vez en la regulación relativa a la homologación de títulos universitarios extranjeros, introduce importantes confusiones debido a la dificultad intrínseca que posee tal exigencia. "Evaluación de las competencias formativas, aparte de tratarse de un elemento novedoso en nuestro sistema educativo universitario, me atrevería a decir que poco calibrado y asentado todavía, es un elemento en el que en todo caso habrán tenido que entrar los docentes de la Universidad expedidora del título en el proceso de evaluación" $"$.

Asimismo, el Real Decreto 967/2014 también introduce una serie de exclusiones dentro de su ámbito de aplicación, que en gran medida, no difiere de la contemplada en el derogado Real Decreto 285/2004 (artículo 3.2 del Real Decreto 967/2014). Así, no se podrá optar a la homologación, declaración de equivalencia o convalidación los títulos o estudios extranjeros sin validez oficial en el país de origen, los que se hayan realizado (en todo o en parte) en centros de España sin autorización para impartir las enseñanzas, los títulos ya homologados en España o los estudios convalidados para continuar estudiando en España, y por último, los títulos obtenidos por reconocimiento de ejercicio profesional en un 15 por ciento de los créditos que constituyen el plan de estudios.

Especial atención merece la exclusión que determina que no pueden ser objeto de homologación, equivalencia o convalidación los títulos obtenidos en centros españoles que carezcan de la debida autorización (artículo 3.2.b) del Real Decreto 967/2014). Disposición en consonancia con lo dispuesto en la LOU de $2007^{86}$. Se hace alusión, pues, a aquellos centros españoles que tienen convenios o acuerdos con Universidades extranjeras. De manera que del tenor del precepto parece que un estudiante que esté en posesión de un título obtenido en un centro no autorizado no puede obtener la homologación, equivalencia o convalidación de tal título, sin precisar el momento temporal de realización de los estudios. Sin embargo, la exclusión no es novedosa, ya que el Estado español siempre ha denegado la homologación de títulos extranjeros obtenidos en una Universidad no española después de que el solicitante hubiera estudiado en un centro español vinculado mediante convenio con la misma, salvo que el centro extranjero estuviera autorizado. Por lo tanto, si un estudiante había obtenido su título de esta forma, se le negaba toda posibilidad de proceso de homologación, e incluso si la estancia en el centro no autorizado hubiera sido parcial.

así exigir a los titulados europeos los requisitos de acceso, que según el propio art. 10 4. [...] no debe[n] exigirse."

${ }^{85}$ LOSTAO CRESPO, F. Op. cit., p. 97.

${ }^{86}$ Artículo 86.3 de la Ley Orgánica 4/2007, de 12 de abril, por la que se modifica la Ley Orgánica 6/2001, de 21 de diciembre, de Universidades: "Los títulos y enseñanzas de educación superior correspondientes a estudios extranjeros realizados, en todo o en parte, en España sólo podrán ser sometidos al trámite de homologación o convalidación si los centros donde se realizaron los citados estudios se hubieran establecido de acuerdo con lo previsto en los apartados anteriores, y las enseñanzas sancionadas por el título extranjero cuya homologación se pretende estuvieran efectivamente implantadas en la Universidad o centro extranjero que hubiera expedido el título. Reglamentariamente, y a los efectos de dicha homologación, el Gobierno regulará las condiciones de acceso a los estudios en dichos centros." 
En abril de 2005 esta cuestión llegó a los tribunales. En concreto, Tribunal Supremo en su Sentencia de 12 abril de $2005^{87}$ se pronunció al respecto. En esta ocasión la Sala de lo Contencioso-Administrativo del Tribunal Superior de Justicia de Madrid desestimó el recurso promovido contra la resolución de la Subdirección General de Recursos Administrativos del Ministerio de Industria y Energía, desestimatoria en el recurso interpuesto contra Resolución de la Subsecretaría, que desestimaba la solicitud de un titulado que pretendía homologar su grado académico, obtenido en la University of Wales Institute Cardiff (Reino Unido), y habilitarse para ejercer en España las profesiones de Ingeniero Industrial e Ingeniero Técnico Industrial. El fundamento de la denegación se basó en que las enseñanzas para la obtención del título fueron impartidas en su totalidad en el Centro de Estudios Superiores de la Fundación San Valero de Zaragoza que tiene suscrito con la Universidad de Cardiff un convenio de naturaleza jurídico-privada, pero sin que dicho centro estuviera constituido en España como Centro Universitario, y no constar en la fecha de expedición del título la correspondiente autorización por parte de las autoridades administrativas españolas.

No obstante, en este caso el interesado no solicitaba la homologación de su título sino el reconocimiento a efectos del ejercicio de la profesión de Ingeniero Industrial e Ingeniero Técnico Industrial. El Tribunal estimó el recurso amparándose en el artículo 2 del Real Decreto $1665 / 1991^{88}$ (vigente hasta el 8 de noviembre de 2008) que como requisito para ejercer en España una profesión regulada por un nacional de un Estado miembro de la Unión Europea únicamente exigía estar en posesión de un título obtenido en un Estado de la Unión Europea, y ello, con independencia del lugar en que los estudios se cursaron, en base al artículo 1 del Real Decreto 1665/1991 ${ }^{89}$. Así pues, se exige la concurrencia de los siguientes requisitos: título, superación de estudios postsecundarios de duración mínima de tres años y que la formación haya sido adquirida en la Unión Europea. Dichos requisitos concurrían en el interesado, por lo que se estimó el recurso de casación que presentó, sin que se declarase la existencia de un fraude de Ley como apelaba la contradefensa ${ }^{90}$.

\footnotetext{
87 Sentencia del Tribunal Supremo de 12 de abril de 2005 (Sala de lo Contencioso-Administrativo, Sección $3^{\text {a }}$ ). Recurso de Casación núm. 6026/2002. Ponente: Sr. Oscar González González.

${ }^{88}$ Real Decreto $1665 / 1991$, de 25 de octubre, por el que se regula el sistema general de reconocimiento de los títulos de Enseñanza Superior de los Estados miembros de la Comunidad Económica Europea que exigen una formación mínima de tres años de duración. [BOE núm. 280, de 22 de noviembre de 1991].

${ }^{89}$ El artículo 1 del Real Decreto 1665/1991 define como título "cualquier título expedido por una Autoridad competente en un Estado miembro, que acredite que el titular ha superado un ciclo de estudios postsecundarios de una duración mínima de tres años en una Universidad, en un Centro de Enseñanza Superior o en otro Centro del mismo nivel de formación y que posee las cualificaciones profesionales requeridas para acceder a una profesión regulada en dicho Estado miembro, siempre que la formación haya sido adquirida principalmente en la Comunidad o el titular tenga una experiencia profesional de tres años acreditada por el Estado miembro que haya reconocido el título".

${ }^{90}$ En relación a ello el derogado Real Decreto 285/2004 provocó gran controversia, ya que en su artículo 5.2 y el artículo 86.3 de la LOU de 2001(se mantiene en la reforma de 2007) disponían que no se podían homologar títulos extranjeros si se había estudiado en centros españoles no autorizados. Sin embargo, tanto el Ministerio de Educación como la Audiencia Nacional empezaron a considerar el momento de la realización de la solicitud y no el momento de ejecución de los estudios en los procedimientos de petición de homologación. De forma que si una persona había estudiado de forma previa a la entrada en vigor de la Ley Orgánica de Universidades de 2001(cuando no se consideraba legalmente la relación entre la homologación del título y la consideración del centro autorizado o no) pero solicitaba la homologación
} 
Al efecto, la LOU de 2001 (y también en su reforma de 2007) estableció que no se podían homologar títulos extranjeros si se había estudiado en centro españoles no autorizados previamente (artículo 86.3 de la vigente LOU). De modo, que sólo a partir de la entrada en vigor de tal norma se podía negar la homologación por tal impedimento. Hasta entonces el Estado español, que negaba sistemáticamente cualquier pretensión en tal sentido, estaba actuando sin cobertura legal. La mencionada sentencia de 12 abril de 2005 confirmaba que antes de la entrada en vigor de la LOU de 2001 había un vacío legal y que las denegaciones del Ministerio de Educación en tal sentido eran irregulares al no contar con amparo legal. La resolución judicial pese a no abordar un proceso de homologación sino de reconocimiento profesional sirvió para sentar jurisprudencia en tal sentido ${ }^{91}$. Posteriormente, diferentes resoluciones judiciales de la Sala de lo Contencioso Administrativo del Tribunal Supremo confirmaron tal doctrina: Sentencia de 19 de junio de $2006^{92}, 16$ de mayo de $2007^{93}$ y de 30 de noviembre de $2007^{94}$.

Sin embargo, el artículo 3.2.b) del vigente Real Decreto 967/2014 que propugna la no homologación, equivalencia o convalidación si se ha estudiado en centro españoles previamente no autorizados puede provocar una nueva confusión y reiterar la situación que ya ocurrió con el anterior Real Decreto 285/2004, de forma que se deniegue la homologación, declaración de equivalencia o convalidación a una persona que opte por alguna de estas figuras habiendo estudiado en un centro no autorizado antes de la entrada en vigor de la LOU de 2001 (aunque el año 2009 el Tribunal Supremo volvió a interpretar como ilegal la aplicación retroactiva de la norma y sentenció que el momento a considerar es el de la realización de los estudios y no la presentación de la solicitud por la que se solicita la homologación. Así, se ha dispuesto en la Sentencia del Tribunal Supremo de 16 de junio de $2009^{95}$, de 21 de julio de $2009^{96}$, de 15 de diciembre de $2009^{97}$ ). Frente a tal situación, la actividad de los tribunales será determinante para despejar las posibles dudas que puedan surgir de la aplicación de tal disposición.

\footnotetext{
después de la entrada en vigor del Real Decreto 285/2004, se invocaba la no autorización del centro como impedimento al proceso de homologación. Como detalla LOSTAO CRESPO, F. Op. cit., p. 100: "Una suerte de aplicación retroactiva de una norma restrictiva de derechos, que volvía a chocar con los cimientos de nuestro sistema jurídico".

${ }^{91}$ Para conocer más jurisprudencia sobre casos concretos de solicitudes de reconocimiento profesional de titulaciones o cualificaciones expedidas en el extranjero vid, CUADRADO ZULOAGA, D. (2009), "Homologación de títulos expedidos en el extranjero y reconocimiento profesional a efectos del ejercicio de la correspondiente actividad", Actualidad administrativa, n ${ }^{\circ} 22$.

${ }^{92}$ Sentencia del Tribunal Supremo de 19 junio 2006 (Sala de lo Contencioso-Administrativo, Sección 7ª). Recurso de Casación núm. 2296/2000. Ponente: Sr. Pablo Lucas Murillo de la Cueva.

${ }^{93}$ Sentencia del Tribunal Supremo de 16 mayo 2007 (Sala de lo Contencioso-Administrativo, Sección $3^{\text {a }}$ ). Recurso de Casación núm. 7093/2004. Ponente: Sr. Manuel Campos Sánchez-Bordona.

${ }^{94}$ Sentencia del Tribunal Supremo de 30 noviembre 2007 (Sala de lo Contencioso-Administrativo, Sección 4a). Recurso de Casación núm. 3767/2005. Ponente: Sr. Ricardo Enríquez Sancho.

${ }^{95}$ Sentencia del Tribunal Supremo de 16 junio 2009 (Sala de lo Contencioso-Administrativo, Sección $4^{\text {a }}$ ). Recurso de Casación núm. 1725/2008. Ponente: Sr. Antonio Martí García.

${ }^{96}$ Sentencia del Tribunal Supremo de 21 julio 2009 (Sala de lo Contencioso-Administrativo, Sección 4aa). Recurso de Casación núm. 1719/2008. Ponente: Sr. Antonio Martí García.

97 Sentencia del Tribunal Supremo de 15 diciembre 2009 (Sala de lo Contencioso-Administrativo, Sección $4^{\text {a }}$ ).Recurso de Casación núm. 4470/2008. Ponente: Sr. Antonio Martí García.
} 
Asimismo, el apartado c) del artículo 3.2 indica como causa de exclusión de homologación, equivalencia, los títulos extranjeros que hayan sido objeto en España de un procedimiento de homologación o de equivalencia a titulación y a nivel académico universitario oficial en los que haya recaído resolución. Aunque para algunos autores esta disposición parece algo confusa, entendemos que el legislador lo que pretende es evitar que si el interesado ha obtenido la homologación o la declaración de equivalencia del título académico extranjero pretendido, no pueda usar ese mismo título para la convalidación de asignaturas en una Universidad española. El fundamento radica en impedir que un mismo título universitario extranjero pueda utilizarse en más de una ocasión para procedimientos distintos.

Por su parte, la Disposición Transitoria Primera $2^{\circ}$ párrafo establece que toda persona que hubiera accedido a un procedimiento de homologación al amparo de las normativas anteriores (Real Decreto 285/2004 y 86/1987) y estando en posesión de una resolución, no tendrá derecho a realizar una nueva solicitud conforme al nuevo Real Decreto. Tal precepto no da respuesta a la idea de si la resolución obtenida ha tenido que ser negativa o positiva, como tampoco se especifica la firmeza de las resoluciones. Sin embargo, entendemos que tal disposición puede suponer una merma en los derechos del universitario extranjero, además, de carecer de sentido que al solicitante al que se le haya negado la homologación de su título universitario extranjero no pueda volver a intentarlo según la nueva normativa. De esta forma si un titulado extranjero ha pretendido homologar su título en España conforme al Real Decreto 86/1987 y sobre tal procedimiento ha recaído resolución desfavorable por no existir una correspondencia clara y determinante entre los contenidos curriculares de su título y los contenidos en el catálogo español, no tendría razonamiento que por aplicación de la mencionada Disposición Transitoria Primera, no pudiera acceder a la nueva homologación o declaración de equivalencia que propone el Real Decreto 967/2004.

Esta disposición es consecuencia de la aplicación de la normativa vigente en el momento en el cual se resuelve el procedimiento para dar efectividad a los títulos extranjeros universitarios. No obstante, resulta cuanto menos cuestionable que no pueda aplicarse retroactivamente la nueva norma al ser más favorable para el interesado. Entendemos que sería de aplicación la denominada retroactividad in bonus al existir una normativa más beneficiosa para el sujeto interesado ${ }^{98}$. Esto es, el Real Decreto 967/2014 permite dar efectividad a un título extranjero en España a través de los nuevos procedimientos diseñados que se han tornado más flexibles que los existentes hasta entonces. La retroactividad in bonus es una institución que pese a no estar recogida en la Constitución española (como sí lo está la irretroactividad in peius) ha sido aceptada por la jurisprudencia y se ha positivizado en nuestro ordenamiento jurídico. En este sentido, la Ley 40/2015 de Régimen Jurídico del Sector Público ${ }^{99}$ contempla la

\footnotetext{
98 Vid, SUÁREZ COLLÍA, J.M. (2006), La retroactividad. Normas jurídicas retroactivas $e$ irretroactivas. Madrid: Editorial Universitaria Ramón Areces. Y CANO CAMPOS, T. (2015) "La potestad sancionadora de la administración: una regulación fragmentaria, incompleta y perniciosa", Documentación Administrativa. Nueva Época, $\mathrm{n}^{\mathrm{o}} \quad 2 . \quad$ [En línea] https://revistasonline.inap.es/index. php?journal=DA\&page=article \&op=view\&path\%5B $\% 5 \mathrm{D}=10275 \& \mathrm{pa}$ th $\% 5 \mathrm{~B} \% 5 \mathrm{D}=10791$.

${ }^{99}$ Ley 40/2015, de 1 de octubre, del Régimen Jurídico del Sector Público. [BOE núm. 236, de 2 de octubre de 2015].
} 
irretroactividad en su artículo 26, reconociendo, pues, el principio constitucional de la irretroactividad in peius que opera como mandato al legislador imponiéndole normas sancionadoras desfavorables con carácter retroactivo y a la Administración que tampoco podrá aplicarlas de tal forma. Así, resulta discutible que la nueva regulación, en cuanto más favorable, no sea aplicable cuando la resolución no goza de firmeza. En este sentido, los tribunales han acogido la idea de que el límite a la retroactividad in bonus se localiza en la firmeza de las resoluciones sancionadoras ${ }^{100}$, de hecho, la Ley 40/2015 en el mencionado artículo 26 habla de "presunto infractor", en clara alusión, pues, a la no existencia de una resolución judicial firme que desvirtúe tal presunción. Así, el límite de la retroactividad in bonus se encuentra en la firmeza de las resoluciones sancionadoras al dirigirse al "presunto infractor", de modo, que cuando exista resolución firme, bien porque no ha sido recurrida bien porque no ha sido confirmada, habría que hablar de infractor sin la debida presunción.

Por su parte, el artículo 3.2 d) del Real Decreto 967/2004 establece como causa de exclusión para la homologación, declaración de equivalencia o convalidación los títulos o estudios expedidos o realizados en el extranjero cuando los títulos obtenidos por reconocimiento de ejercicio profesional sean superior al 15 por ciento del total de créditos que constituyen el plan de estudios. El mismo porcentaje es el que contempla el Real Decreto 1393/2007, en su artículo 6.3 ${ }^{101}$, para reconocer créditos a partir de experiencia profesional o laboral y de enseñanzas universitarios no oficiales. Por lo que entendemos que el Estado español pretende extralimitarse de sus competencias y entrar a valorar la forma y las condiciones en qué otros sistemas universitarios configuran sus planes de estudios, en vez de limitarse, como parece más lógico, a comprobar la legitimidad del título extranjero y a estudiar su contenido. Máxime cuando el Real Decreto 1393/2007 otorga a las Universidades la capacidad para que en sus planes de estudios establezcan prácticas que pueden llegar hasta el 25 por ciento de los créditos del título universitario (artículo 12 del Real Decreto 1393/2007). De modo que España se niega a reconocer títulos extranjeros que tienen más de un 15 por ciento de créditos como prácticas profesionales, pero permite que en sus estudios oficiales éstas sean hasta del 25 por ciento.

Otra novedad que establece la actual regulación de las homologaciones radica en la necesidad de acreditación de competencia lingüística para poder obtener la homologación que habilita al ejercicio de profesiones reguladas (artículo $10.3 \mathrm{~b}$ ) del Real Decreto 967/2014). Sin embargo, el precepto no detalla el nivel requerido; además de no concretarse los idiomas extranjeros específicos. Para ello, se ha tenido que dictar

\footnotetext{
${ }^{100}$ Sentencia del Tribunal Supremo de 22 septiembre 1988 (Sala de lo Contencioso-Administrativo, Sección $1^{a}$ ), ponente: Sr. Rafael de Mendizábal Allend. Y Sentencia de la Audiencia Nacional de 22 noviembre 2002 (Sala de lo Contencioso-Administrativo, Sección 1ª), recurso de apelación núm. 65/2002, ponente: Sr. Manuel García Fernández-Lomana.

${ }^{101}$ Artículo 6.3. del Real Decreto 1393/2007, de 29 de octubre, por el que se establece la ordenación de las enseñanzas universitarias oficiales: "El número de créditos que sean objeto de reconocimiento a partir de experiencia profesional o laboral y de enseñanzas universitarias no oficiales no podrá ser superior, en su conjunto, al 15 por ciento del total de créditos que constituyen el plan de estudios. El reconocimiento de estos créditos no incorporará calificación de los mismos por lo que no computarán a efectos de baremación del expediente."
} 
una Orden Ministerial ${ }^{102}$ que establece los requisitos necesarios para acreditar la competencia lingüística.

\section{Procedimiento de homologación, declaración de equivalencia, convalidación de títulos extranjeros en España y correspondencia a nivel MECES.}

El procedimiento de homologación de títulos extranjeros y figuras afines en España es un proceso complejo que implica a dos sistemas educativos, y por ello, precisa de una adecuada regulación que simplifique tal trámite y permita la movilidad estudiantil y la atracción de talento a nuestro país. En España, la última década estuvo marcada por una gran afluencia de extranjeros que propició un aumento considerable de las solicitudes de homologación de títulos universitarios obtenidos en instituciones educativas de fuera de nuestras fronteras ${ }^{103}$. Con el objetivo de lograr la ansiada convergencia europea y el llamamiento del talento internacional a España, el nuevo Real Decreto 967/2014 intenta diseñar un procedimiento ágil para homologar, equivaler y convalidar los estudios superiores en España y para lograr la correspondencia a nivel MECES.

El procedimiento para determinar la homologación, equivalencia y convalidación de los títulos oficiales se encuentra regulado en su totalidad en el Capítulo II del Real Decreto $967 / 2014^{104}$. Así, son susceptibles de homologación aquellos títulos extranjeros de educación superior que den acceso al ejercicio de alguna de las profesiones reguladas. Por su parte, la declaración de equivalencia de un título extranjero de educación superior a titulación y a nivel académico universitario oficial se solicitará respecto de aquellas titulaciones de Grado o de Máster que no den acceso a una profesión regulada. La convalidación se reputará de estudios extranjeros por estudios universitarios españoles parciales, cuya competencia recae en la Universidad española a la que el interesado haya solicitado dicha convalidación para proseguir sus estudios.

En el caso de la homologación y declaración de equivalencia de estudios extranjeros, el procedimiento se inicia mediante solicitud del interesado ante el Ministerio de

\footnotetext{
102 Artículo 17.1. de la Orden ECD/2654/2015, de 3 de diciembre, por la que se dictan normas de desarrollo y aplicación del Real Decreto 967/2014, de 21 de noviembre. [BOE núm. 296, de 11 de diciembre de 2015].

${ }^{103}$ Los datos del Ministerio de Educación recogen que en el año 2013 se emitieron un total de 22.841 resoluciones de homologación, de las cuales, el 57\% fueron favorables. Tan sólo el 9\% se denegaron y el $20 \%$ quedaron sujetos a la realización y superación de una prueba. La gran mayoría de las resoluciones favorables de homologación de titulaciones universitarias extranjeras se dictaron para títulos cuyos países principales de expedición eran Italia y Venezuela. Lamentablemente desde el año 2014 el Estado español no ha hecho público los datos relativos a esta cuestión, por lo que no es posible hacer una comparativa actualizada en tal sentido. Vid, SUBDIRECCIÓN GENERAL DE ESTADÍSTICA Y ESTUDIOS DEL MINISTERIO DE EDUCACIÓN, CULTURA Y DEPORTE, "Las cifras de la educación en España. Curso 2014-2015 (Edición 2017)”, Mecd.gob.es, 22 de febrero de 2017. [En línea] https://www.mecd.gob.es/servicios-al-ciudadano-mecd/estadisticas/educacion/indicadores-publicacionessintesis/cifras-educacion-espana/2014-15.html.

${ }^{104} \mathrm{El}$ interesado que pretenda reconocer sus estudios universitarios realizados en el extranjero puede acudir directamente a la página web del Ministerio de Educación, Cultura y Deporte (www.mecd.gob.es), concretamente en el apartado "Títulos extranjeros universitarios" donde se localiza toda la información necesaria sobre el procedimiento administrativo, incluyendo la normativa aplicable, modelo de solicitud y otros datos destacables. El trámite se puede realizar de manera telemática a través de dicha plataforma oficial o cumplimentando la solicitud normalizada disponible también de manera online.
} 
Educación, Cultura y Deporte (artículo 8 del Real Decreto 967/2014). La instrucción del procedimiento se oficiará por la Subdirección General de Títulos y Reconocimiento de Cualificaciones (artículo 9 del Real Decreto 967/2014). Eso sí, la resolución de la homologación de títulos extranjeros y la equivalencia a titulación y a nivel académico universitario oficial deberán tener en cuenta una serie de requisitos comunes y específicos (artículo 10 del Real Decreto 967/2014).

La Subdirección General de Títulos y Reconocimiento de Cualificaciones del Ministerio de Educación solicitará a la ANECA un informe motivado ${ }^{105}$, según los criterios establecidos en el artículo 10 del Real Decreto 967/2014 (artículo 11.1 del Real Decreto $967 / 2014$ ), aunque hay una serie de excepciones a la necesidad de solicitar informe a la Agencia Nacional (artículo 12 del Real Decreto 967/2014). Dichos documentos pueden ser individuales, si versa sobre un expediente administrativo concreto; o bien, generales, si se refieren a una determinada titulación extranjera (artículo 11.2. del Real Decreto 967/2014). La Agencia tendrá un plazo máximo de tres meses para emitir el informe, que será preceptivo y determinante (artículo 11.4 del Real Decreto 967/2014).

Finalmente, el procedimiento termina con una resolución que puede ser positiva, negativa o mixta si está condicionada a la realización y superación de una formación extra (artículo 13 del Real Decreto 967/2014); esto es, si se detectan carencias en la formación acreditada para la obtención del título extranjero con respecto a la exigida para el español con el que se pretende homologar o equivaler, pero tal déficit no goza de gran entidad como para denegar la solicitud, ésta queda condicionada a que se superen unos requisitos formativos complementarios. Éstos podrán consistir en una prueba de aptitud, la realización de un período de prácticas, la presentación de un proyecto o superar una serie de cursos (artículo 16 de Real Decreto 967/2014).

El plazo para resolver y notificar la resolución será de seis meses a partir de la fecha de entrada de la solicitud en el registro del Ministerio de Educación (artículo 14 Real Decreto 967/2014). El señalado plazo de tres meses previsto para emitir el informe técnico suspende el plazo de resolución del procedimiento.

\footnotetext{
${ }^{105}$ A la hora de proceder a una homologación o declaración de equivalencia, la ANECA desarrolla su trabajo en diferentes comisiones. En este sentido, para la homologación las comisiones se estructuran en tres niveles. El primer nivel corresponde a una Comisión formada por representantes de la ANECA, presidida por el director del ente y formada por cinco vocales. Cada uno en representación de una rama de conocimiento (Artes y Humanidades, Ciencias, Ciencias de la Salud, Ciencias Sociales y Jurídicas e Ingeniería y Arquitectura). Su función principal es garantizar la coherencia en las actividades que realicen las comisiones del segundo nivel. En el segundo nivel se localizan cinco comisiones, una por cada rama de conocimiento. Cada una de ellas está formada por un presidente y un número de vocales que varía de una a otra. La misión de éstas es la de garantizar la consistencia de las actuaciones realizadas por el tercer nivel. Y en el último nivel se encuentran casi sesenta subcomisiones en las que se integran los diferentes títulos objeto de correspondencia. Cada comisión posee un presidente, un representante del Consejo de Colegios Profesiones o asociaciones profesionales, en su caso; y un representante de la conferencia de decanos/directores de los títulos objeto de correspondencia. En este estrato se elaboran los informes de correspondencia y homologación debidamente motivados. En el caso de optar por equivalencias la estructura del nivel primero y segundo se mantienen idénticas a las utilizadas en el procedimiento de homologación. Vid, ANECA, "Equivalencia y correspondencia de títulos", Aneca.es, 26 de marzo de 2015. [En línea] http://www.aneca.es/Documentos-y-publicaciones/Boletines/Noticiasboletin/Equivalencia-y-correspondencia-de-titulos.
} 
Con respecto a la declaración de equivalencia al nivel de Doctor, la Disposición Adicional Quinta del Real Decreto 967/2014 estable que serán las Universidades quienes ostentarán tal competencia. El procedimiento, establecido según las normas estatutarias de las universidades, se iniciará mediante solicitud del interesado, dirigida al Rector de la Universidad elegida. La concesión de la equivalencia se acreditará mediante certificado expedido por la Universidad y en él se hará constar el título extranjero poseído por el interesado y la Universidad de procedencia. Además, la equivalencia se podrá solicitar de forma simultánea en más de una Universidad, pero el título extranjero declarado ya equivalente no podrá ser sometido a un nuevo trámite de equivalencia en otra Universidad. No obstante, si ésta ha sido denegada, el interesado podrá iniciar un nuevo expediente en otra Universidad española. Asimismo, según recoge tal disposición, la equivalencia al nivel de Doctor no implica la homologación, la declaración de equivalencia o reconocimiento de otro título extranjero que posea el interesado, ni el reconocimiento en España a nivel distinto al de Doctor.

Por su parte, la competencia para la convalidación de estudios extranjeros por estudios universitarios españoles parciales recae en la Universidad española a la que el interesado haya solicitado dicha convalidación para proseguir sus estudios, de acuerdo con los criterios que fije el Consejo de Universidades (artículo 17 del Real Decreto 967/2014). Se podrán convalidar los estudios superiores extranjeros que cumplan los criterios fijados por cada Universidad y que no incurran en las causas de exclusión establecidas en el Real Decreto 967/2014, sin perjuicio de que hayan terminado o no con la obtención de un título (artículo 18 del Real Decreto 967/2014).

Si lo que se pretende es determinar la correspondencia a los niveles del Marco Español de Cualificaciones para la Educación Superior de los títulos oficiales de Arquitecto, Ingeniero, Licenciado, Arquitecto Técnico, Ingeniero Técnico y Diplomado, este procedimiento se iniciará de oficio por la Dirección General de Política Universitaria; por propia iniciativa, como consecuencia de orden superior, a petición razonada de otros órganos o por denuncia del interesado (artículo 19 del Real Decreto 967/2014). La instrucción del procedimiento corresponderá, de oficio, a la Dirección General de Política Universitaria (artículo 20 del Real Decreto 967/2014). Será este órgano el encargado de solicitar informe preceptivo y determinante a la ANECA (artículo 21.1 del Real Decreto 967/2014), la cual, tendrá que informar en un plazo máximo de tres meses, aunque dicho plazo puede prorrogarse. Una vez emitido el informe por la ANECA, la Dirección General de Política Universitaria solicitará el informe del Consejo de Universidades, que es preceptivo, pero no vinculante, para resolver el procedimiento (artículo 21.2 del Real Decreto 967/2014). Los informes de la ANECA realizarán una comparación entre la formación requerida para obtener el título extranjero y la exigida en España para tener el título con el que se pretende homologar, así como su duración o carga horaria (artículo 22 del Real Decreto 967/2014). No obstante, antes de que finalice la fase de instrucción del procedimiento administrativo, la Dirección General de Política Universitaria abre un período de información pública que no podrá ser inferior a 20 días hábiles (artículo 23 del Real Decreto 967/2014). Además, en los casos donde existe representación profesional, se informará a los Consejos Generales y Colegios 
profesionales nacionales, en su caso, de la apertura de información público para que emitan informe, que no será vinculante ${ }^{106}$.

Finalmente, la Dirección General de Política Universitaria elevará al Ministerio de Educación la propuesta de resolución del procedimiento, la cual, será aprobada por el Ministerio mediante acuerdo del Consejo de Ministros. La resolución que ponga fin al procedimiento será motivaba, con los hechos y fundamentos de derecho (artículo 24.3 del Real Decreto 967/2014) y se publicará en el Boletín Oficial del Estado para, posteriormente, inscribir la resolución de reconocimiento de correspondencia en el Registro de Universidades, Centros y Títulos (artículo 24 del Real Decreto 967/2014). El plazo máximo para resolver y publicar la resolución del procedimiento es de seis meses (artículo 25 del Real Decreto 967/2014).

\section{Conclusiones.}

$1^{\circ}$. Pese a los cambios legislativos producidos en los últimos tiempos, el significado y las características esenciales de los títulos universitarios oficiales se han mantenido inalterables, aunque el propio concepto de título universitario no es definido explícitamente por nuestro ordenamiento jurídico. Su significado se deduce de diferentes disposiciones de la vigente LOU y del Real Decreto 1393/2007 que regula la enseñanza universitaria. Este último texto normativo introduce, además, una importante novedad en la clasificación de los títulos superiores, ya que éstos pueden ser de tres tipos: Grado, Máster o Doctor. Junto a ello, otra de las características fundamentales de los títulos universitarios españoles que aporta el mencionado Real Decreto es la orientación que pueden poseer, ya sea profesional, si habilita para el ejercicio de una profesión; o académica, cuando es necesario la realización de un Máster para poder acceder a determinadas profesiones reguladas.

$2^{\circ}$. El actual marco normativo en relación a los títulos universitarios se encuentra localizado, principalmente, en la LOU, la cual, reconoce la autonomía universitaria para la expedición de los títulos oficiales y propios. En desarrollo de la citada Ley se promulgó el Real Decreto 1393/2007 que ordena las enseñanzas universitarias y desarrolla la estructura de los estudios superiores y la verificación y acreditación de los títulos universitarios españoles. No obstante, en la actualidad, la regulación de los sistemas que dan efectividad a los títulos superiores extranjeros nace en virtud de la reforma que sufre la LOU en 2007 y en su posterior norma de desarrollo, el Real Decreto 967/2014, que diferenció entre tres conceptos jurídicos: homologación, equivalencia y convalidación. En virtud del primero, se dispone la homologación de un título extranjero a un título universitario español que dé acceso a una profesión regulada en España. Por su parte, la declaración de equivalencia de un título extranjero se establece para las titulaciones que no habilitan para el acceso a una profesión regulada, con la posibilidad de obtener la equivalencia a nivel académico y a la titulación correspondiente a un área y campo específico en los que pueden agruparse los diferentes títulos universitarios. Por último, la convalidación supone el reconocimiento oficial de

\footnotetext{
${ }^{106}$ Para conocer más sobre este procedimiento vid, ANECA, "Equivalencia y correspondencia de títulos". Aneca.es, 26 de marzo de 2013. [En línea] http://www.aneca.es/Documentos-ypublicaciones/Boletines/Noticias-boletin/Equivalencia-y-correspondencia-de-titulos.
} 
la validez de estudios superiores realizados en el extranjero, hayan finalizado o no con un título, respecto de estudios universitarios españoles que permitan proseguir dichos estudios en una Universidad española. A su vez, el Real Decreto 967/2014 también ordena el procedimiento para determinar la correspondencia a los niveles del Marco Español de Cualificaciones para la Educación Superior de los títulos oficiales anteriores al proceso de Bolonia. De esta forma el Real Decreto vino a colmar el vacío que había supuesto la desaparición del catálogo oficial de títulos universitarios por la integración de España al EEES.

Así, el Estado español condensa la regulación de esta materia en los citados textos normativos. No obstante, con la existencia de un Catálogo oficial de títulos universitarios las referencias de los mismos se encontraban localizadas en dicho documento, sin embargo, tras su eliminación las reseñas se vuelven más difusas. Así, por ejemplo, en cuanto a los aspectos profesionales de los títulos habrá que acudir a la normativa específica que regula cada una de las profesiones mencionadas en el Anexo I del Real Decreto 967/2014, lo cual proporciona una mayor dispersión normativa.

$3^{\circ}$. El régimen de homologación, y lo que hemos llamado figuras afines, de títulos universitarios extranjeros en España ha experimentado notables transformaciones en las últimas décadas, transitando de un modelo restrictivo a una regulación más elástica y adaptada a las circunstancias sociales, normativas y académicas. Así, se ha evolucionado desde un modelo clásico y encorsetado donde se valoraba, esencialmente, los contenidos de los estudios (Real Decreto 86/1987); a un modelo más flexible que junto a la homologación clásica (a los títulos universitarios localizados en el catálogo oficial) se contemplaba también una homologación general, llamada de nivel (Real Decreto 285/2004). Sin embargo, la adaptación del proceso de Bolonia a nuestro país, y con él la desaparición del catálogo oficial de titulación introdujo una importante reforma, ya que los sistemas de reconocimiento de títulos están estrechamente vinculados a la estructuración de la enseñanza universitaria. Así se ha llegado al actual modelo, configurado en base al Real Decreto 967/2014, que diferencia entre homologación, para las titulaciones que dan acceso a profesiones reguladas; y para el resto de supuesto, la declaración de equivalencia (la antigua homologación de nivel). De forma que actualmente sólo se puede usar el término homologación para referirse al reconocimiento de títulos que habilitan al ejercicio profesional reglado. Una evolución positiva (aunque la vigente norma también recoge exclusiones e incompatibilidades restrictivas) que permite reconocer la condición genérica de universitario en aras de lograr la aplicación práctica del proyecto europeo y una movilidad internacional acorde con la nueva realidad social y profesional.

$4^{\circ}$. El nuevo procedimiento administrativo diseñado para lograr la homologación, declaración de equivalencia o convalidación se ha intentado dotar de mayor agilidad según se desprende de la Exposición de Motivos del Real Decreto 967/2014. No obstante, el plazo máximo para resolver mantiene la misma duración que aparecía en el anterior Real Decreto 285/2004, la cual, es de 6 meses junto con una suspensión máxima de tres meses para la emisión de los informes técnicos pertinentes. Además, el principal protagonismo en el procedimiento de homologación y declaración de equivalencia recae en el Ministerio de Educación. El papel de la Universidad se circunscribe al procedimiento de convalidación de estudios extranjeros por estudios 
universitarios españoles parcial, ya que la competencia la ostenta en la Universidad española donde el interesado pretenda proseguir sus estudios, al igual que ocurría anteriormente. No obstante, con la desaparición del Catálogo oficial de títulos universitarios y la instauración de un sistema más abierto de registro de los mismos, hubiera sido más coherente que el procedimiento de homologación hubiera pasado a ser competencia de las Universidades. Pero parece que el Estado español recela de estas instituciones y prefiere arrogarse competencias en vez de confiar en las Universidades. Por su parte, para la declaración de equivalencia al nivel de Doctor, la competencia recae sobre la Universidad, como ya ocurría anteriormente (Disposición Adicional Quinta del Real Decreto 967/2014).

\section{Bibliografía.}

AGUDO ZAMORA, M.J. (2015), "La estructura 3 +2 en los títulos universitarios como amenaza y oportunidad de desarrollo del derecho a la autonomía académica de las Universidades", Revista general de derecho constitucional, $\mathrm{n}^{\mathrm{o}}$ 21. [En línea] http://www.iustel.com/v2/revistas/detalle_revista.asp?id_noticia=416713.

BLÁZQUEZ RODRÍGUEZ, I. (2006), La educación y la formación profesional de los inmigrantes. IX Jornadas Autonómicas de Derecho Internacional Humanitario. Córdoba: Universidad de Córdoba.

BOK, D. (2010), Universidades a la venta: la comercialización de la educación superior. Valencia: Publicacions de la Universitat de València.

CABALLERO GEA, J.A. (2005), Asilo. Extranjería, inmigración. Homologación de títulos extranjeros. Nacionalidad. Síntesis y ordenación de la doctrina de los tribunales. Madrid: Dykinson.

CANO CAMPOS, T. (2015) "La potestad sancionadora de la administración: una regulación fragmentaria, incompleta y perniciosa", Documentación Administrativa. $\begin{array}{lllll}\text { Nueva Época, } & \mathrm{n}^{\mathrm{o}} & 2 . & \text { [En }\end{array}$ https://revistasonline.inap.es/index.php?journal=DA\&page=article\&op=view\&path $\% 5$ $\mathrm{B} \% 5 \mathrm{D}=10275 \&$ path $\% 5 \mathrm{~B} \% 5 \mathrm{D}=10791$.

CALVO PÉREZ, B. y MICHAVILA PITARCH, F. (2000), La Universidad española hoy. Madrid: Fundación Alfonso Martín Escudero.

CARRILLO DONAIRE, J.A. (2007), La diferenciación jurídica entre títulos académicos y profesionales. II Congreso de la Asociación Española de Profesores de Derecho Administrativo. Santander: Universidad Internacional Menéndez Pelayo.

CATALÁ RUBIO, S. (2015), “Algunos elementos de reflexión sobre la Universidad española”, Encuentros multidisciplinares, $\mathrm{n}^{\circ}$ 49, pp. 1-6. [En línea] https://repositorio.uam.es/bitstream/handle/10486/678636/EM_49_5.pdf?sequence=1\&i sAllowed=y. 
CUADRADO ZULOAGA, D. (2009), "Homologación de títulos expedidos en el extranjero y reconocimiento profesional a efectos del ejercicio de la correspondiente actividad", Actualidad administrativa, $\mathrm{n}^{\circ} 22$.

DEL CAMPO, S., MUÑOZ, E., BERZOSA, C., COTARELO, R., RUBIO LARA, J.M., LAPORTA, F., MYRO, R., Y SOLÉ, C. (2013), "La ANECA y la crisis de la Universidad Española", Temas para el Debate, n 229, págs. 42-49.

FERNANDEZ LIRIA C. y SERRANO GARCÍA C. (2009), El Plan Bolonia. Madrid: Catarata.

FERNANDEZ-LLEBREZ, F. (2010), "El Plan Bolonia y la reforma de la Universidad", Pagina Abierta, ${ }^{\circ}{ }^{207}$. [En línea] http://www.pensamientocritico.org/ferfer0410.html.

FERLUGA, G. "Avalancha de recursos contra la homologación de títulos extranjeros". Cinco Días. 2 de marzo de 2015. [En línea] https://cincodias.elpais.com/cincodias/2015/02/27/economia/1425049969_540904.html.

FRAILE ARANDA, A. (2006), "El sistema universitario europeo como modelo posible para la educación superior latinoamericana", Revista Electrónica de Investigación Educativa, ${ }^{\circ}$ 1, vol. 8. [En línea] http://www.redalyc.org/articulo.oa?id=15508103.

GARCÍA-VELASCO GARCÍA, F.J. (2007), "El Proceso de Bolonia: situación actual”, Revista de derecho de la Unión Europea, $\mathrm{n}^{\circ}$ 12. [En línea] http://revistas.uned.es/index.php/REDUE/article/view/12497/11698.

GONZÁLEZ MIGUEL, R. (2007), "Homologación, convalidación y reconocimiento de títulos y estudios Extranjeros en España", Revista de Derecho de la Unión Europea, $\mathrm{n}^{\mathrm{o}} 12 \cdot \mathrm{p} .87-115$.

HERNÁNDEZ DÍAZ, J.M. (2014), "Los espacios de la universidad española", Cuadernos del Instituto Antonio de Nebrija de Estudios sobre la Universidad. CIAN, vol. $17, \quad \mathrm{n}^{\mathrm{o}} 1, \quad \mathrm{pp}$. 81-100. [En línea] https://erevistas.uc3m.es/index.php/CIAN/article/view/1971/940.

LASPALAS, J. (2002), "La eterna 'crisis' universitaria: a propósito de dos libros recientes", ESE. Estudios sobre educación, $\mathrm{n}^{\mathrm{o}}$ 2, p.207-2I5. [En línea] http://dadun.unav.edu/bitstream/10171/8106/1/Notas\%205.pdf.

LOSTAO CRESPO, F. (2016), "La homologación de títulos extranjeros en España, evolución del sistema y restricciones injustificadas", Revista electrónica del Departamento de Derecho de la Universidad de La Rioja, $\mathrm{n}^{\circ}$ 14, p. 85-97. [En línea] http://www .unirioja.es/dptos/dd/redur/numero14/lostao.pdf. 
LOPERENA ROTA, D. (2010), "Los retos de Bolonia", Revista Vasca de Administración Pública, $\mathrm{n}^{\mathrm{o}}$ 86, 2, p. 121-132. [En línea] https://www.euskadi.net/r61s20001x/es/t59aWar/t59aMostrarFicheroServlet?t59aIdRevista=2\&R01HNoPortal=true $\&$ t59aTipoEjemplar $=\mathrm{R} \& \mathrm{t} 59 \mathrm{aSec}$ ion $=38 \& \mathrm{t} 59 \mathrm{aContenido}=9 \& \mathrm{t} 59 \mathrm{aCorrelativo}=1 \& \mathrm{t} 59 \mathrm{a}$ Version=1\&t59aNumEjemplar=86.

MOYA ESCUDERO, M. (2001), Comentario sistemático a la ley de extranjería. Granada: Comares.

MOYA ESCUDERO, M. (1999), Los derechos de los trabajadores no comunitarios en España. Granada: Comares.
MUÑOZ-CANTERO,
J.M. y POZO,
C. (2014), "El
escenario

de la calidad en la Universidad española: de dónde venimos y hacia dónde vamos", Revista Electrónica Interuniversitaria de Formación $\quad$ del Profesorado, $\mathrm{n}^{\mathrm{o}}$ 17 (3), pp.1-16. [En línea] http://revistas.um.es/reifop/article/view/204011/165141.

PÉREZ DEL BLANCO, G. (2005), "Estructura y titulaciones de Educación Superior en España”, Proyecto sobre Homologación y reconocimiento de títulos de educación superior en Iberoamérica. Organización de Estados Iberoamericanos, OEI. [En línea] www.oei.es/historico/homologaciones/espana.pdf.

SALABURU, P. (2007), La Universidad en la encrucijada. Madrid: Academia Europea de Ciencias y Artes, p.589.

SALAS VELASCO, M. (2010), "Financiación y crítica de la Universidad española actual", Crítica, año 60, $\mathrm{n}^{\circ}$. 969, pp. 19-21. [En línea] http://www.revistacritica.com/administrator/components/com_avzrevistas/pdfs/03bf4d8eabadb888af70382 7454d0b86-969-La-Universidad-y-sus-contradicciones---Despu--s-de-Bolonia--qu----sept.oct\%202010.pdf.

SUÁREZ ORDÓÑEZ, L.E. (2015), "Los retos de la profesión de geólogo ante la nueva legislación de títulos universitarios y profesionales", Tierra y tecnología: revista de información geológica, $\quad \mathrm{n}^{\mathrm{o}} \quad 46 . \quad$ [En $\quad$ línea] http://www .aufop.com/aufop/revistas/indice/digital/178.

SUÁREZ COLLÍA, J.M. (2006), La retroactividad. Normas jurídicas retroactivas e irretroactivas. Madrid: Editorial Universitaria Ramón Areces.

VAN GRIEKEN SALVADOR, R. (2014), "El Espacio Europeo de Educación Superior, la gestión de la calidad y su impacto en la oferta de títulos universitarios", Nueva revista de política, cultura y arte, $\mathrm{n}^{\mathrm{o}}$ 151, 2014, pp. 277-288. [En línea] https://reunir.unir.net/bitstream/handle/123456789/4444/El\%20espacio\%20europeo.pdf ?sequence $=1 \&$ isAllowed $=\mathrm{y}$.

VÁZQUEZ-REINA, M. "Homologar el grado de un título universitario extranjero". Consumer.es. 7 de febrero de 2008. [En línea] http://www .consumer.es/web/es/educacion/universidad/2008/02/07/174381.php. 